\title{
Sources, Fate, and Plant Uptake in Agricultural Systems of Per- and Polyfluoroalkyl Substances
}

\author{
M. Christina Schilling Costello ${ }^{1,2} \cdot$ Linda S. Lee ${ }^{1,2}$ (D)
}

Accepted: 26 October 2020

(C) The Author(s) 2020

\begin{abstract}
Purpose of Review Per- and polyfluoroalkyl substances (PFAS) are a family of $>4700$ recalcitrant compounds, many of which are ubiquitous in the environment. This review aims to (1) identify PFAS sources and fate processes relevant to agricultural systems and (2) expand on plant uptake mechanisms and plant responses to PFAS.

Recent Findings The number of PFAS being quantified in studies involving soil, water, and plants is increasing. Transformation of precursors that tend to stay in the rhizosphere can lead to long-term PFAS reservoir to plants. Some PFAS are readily taken up, particularly the shorter-chain PFAS, and can evoke metabolic responses and phytotoxic effects at high concentrations. PFAS translocation from roots to shoots occurs through both active and passive transport mechanisms. Both PFAS uptake and effects vary between and within species.

Summary As new PFAS emerge, it will be necessary to continue expanding the list of PFAS quantified in land-applied media and assessing their accumulation potential in plants. While controlled laboratory or greenhouse studies have merit, comprehensive field studies are needed to provide clarity on PFAS fate and their relative risk in agricultural systems. Field studies should include identifying site-specific PFAS sources, quantifying a broader suite of PFAS and identifying potential precursors, evaluating plant uptake of replacement PFAS, reporting of soil properties and climatic conditions, and assessing risk of impacts to source and irrigation waters. This information can be utilized to inform future studies towards evaluating and mitigating risks to our food chain associated with PFAS in agricultural systems.
\end{abstract}

Keywords PFAS $\cdot$ PFOS $\cdot$ PFOA $\cdot$ Soil amendments $\cdot$ Phytotoxicity $\cdot$ Crops $\cdot$ Vegetables

\section{Introduction}

Per- and polyfluorinated alkyl substances (PFAS) are a widely utilized chemical family [1-3] now referred to as forever chemicals due to their high thermal and chemical stability as well as minimal biodegradability [4]. The perfluoroalkyl chain length $\left(\mathrm{C}_{\mathrm{n}} \mathrm{F}_{2 \mathrm{n}+1-}\right)$, the functional head group (e.g., carboxylic acid, sulfonate, alcohol, phosphate, amino, or other groups), which may be attached to a nonfluorinated hydrocarbon entity, and structural differences in the fluoroalkyl chain itself

This article is part of the Topical Collection on Emerging Contaminants

Linda S. Lee

1slee@purdue.edu

1 Ecological Sciences and Engineering IGP, Purdue University, West Lafayette, IN 47907, USA

2 Department of Agronomy, Purdue University, 915 W. State St, West Lafayette, IN 47907, USA (e.g., branching, ether moiety) govern their behavior, subclassification, and nomenclature [5]. Some PFAS are highly bioaccumulative and have been reported in blood serum and breast milk of humans throughout the globe [6-8] and have been associated with adverse health effects [9]. Two classes within the PFAS family that have received the most attention are the perfluoroalkyl sulfonic acids (PFSAs) and the perfluoroalkyl carboxylic acids (PFCAs) [10•] of which perfluorooctane sulfonic acid (PFOS) and perfluorooctanoic acid (PFOA), respectively, are the most researched to date. Due to their highly bioaccumulative nature, PFOS and PFOA have been voluntarily phased out and are on the Stockholm Convention persistent organic pollutant lists Annex B (restricted) and Annex A (eliminated), and perfluorohexane sulfonic acid (PFHxS) is under review [11]. A range of less studied and often more mobile PFAS that are substitutes for PFOS and PFOA [12] have been found to be equally persistent and often with similar adverse effects, albeit often at higher concentrations [9], thus leading to additional management and regulatory challenges. 
The primary PFAS exposure routes researched to date are drinking water, meat, fish, milk, food packaged in PFAScontaining materials, and indoor dust inhalation [13-16]. More recently, research has included evaluating PFAS exposure from commonly consumed agricultural products (grains, cereals, vegetables, fruits); therefore, it is crucial to understand PFAS sources to plants and the processes controlling how much of each PFAS is taken up by various plant types. Sources of PFAS to agricultural field crops consist of atmospheric deposition via precipitation or particle-bound PFAS, and absorption from the gaseous phase [17, 18], irrigation with contaminated well water or treated wastewater effluent [19-23], pesticides [24•,25], aqueous film-forming foams (AFFFs) used to extinguish fires [26], and land-applied sewage sludge or biosolids [27•, 28-32, 33•], as well as industrial or municipal compost $[34,35]$. Likewise, food grown in hydroponic and greenhouse systems can be impacted by contaminated water as well as other sources. Relative PFAS contributions from different sources will vary depending on location-specific activities and facilities. For example, PFAS contributions from atmospheric deposition have been especially concerning for crops grown near fluorochemical manufacturing facilities [36, 37]. AFFFs are typically the major PFAS source of highly contaminated water near fire training areas; however, impacts to agriculture are generally limited to irrigation with AFFFcontaminated water [26] which could significantly increase exposure risks [38]. Much less is known about the relative PFAS contribution to crops from land-applied biosolids and composts, which serve as both a valuable resource for improving crop yields and a waste management strategy. Also, factors and mechanisms controlling PFAS uptake by plants are not well understood. A critical understanding of these sources and mechanisms is necessary to determine the associated risks, trade-offs, and need for regulatory action [39-41].

\section{Aim and Scope}

This review will address PFAS in agricultural systems with an emphasis on land application scenarios, PFAS reservoirs in the rhizosphere, soil-plant transfer, and plant health. A recent review by Ghisi et al. [42•] summarized research on PFAS uptake and occurrence in grains, vegetables, and fruit prior to 2018 with an emphasis on comparing bioaccumulation trends between plants and impacts of environmental factors with a primary focus on $\mathrm{C} 4$ and C8 PFCAs and PFSAs. Studies after 2018 have addressed an expanded list of PFAS and began to address precursor contributions to plant uptake. Precursors are PFAS that can degrade to PFCAs or PFSAs, which are the terminal metabolites and collectively referred to as perfluoroalkyl acids (PFAAs). Precursors are often less mobile than PFAAs, thus they can serve as a PFAA reservoir in the rhizosphere. The previous review did not include several field studies that provide valuable information on soil-plant transfer of PFAS under field conditions. In addition, insight into uptake mechanisms and effects to plant health were not specifically addressed. Therefore, this review expands upon the work by Ghisi et al. [42•] accordingly. In addition, hydroponic, pot, and field studies will be compared and contextualized to inform future studies. Recent studies on uptake of PFAS in different agricultural plants are synthesized and discussed in light of previously hypothesized uptake mechanisms and trends. Furthermore, studies on plant responses to PFAS contamination are discussed. Immediate data gaps are highlighted to guide future plant uptake studies, clarify potential PFAS sources in agricultural systems, and better inform relative risk of PFAS exposure through our food chain.

\section{The Expanding List of PFAS}

At least 4700 PFAS have been used in industrial and commercial processes and thus potentially released to the environment $[3,43]$. PFAS include anionic, cationic, zwitterionic, and neutral compound groups with a range of functional groups (e.g., carboxylic acid, sulfonic acid, ether sulfonate, sulfonamide, sulfonamido acetic acid, phosphate diester, acrylate, amido ammonium salt, amido betaine, and others) [44, 45]. In addition, for a given PFAS, there can be multiple isomers depending on the manufacturing process, e.g., PFOS produced from an electrochemical fluorination process yields multiple branched isomers in addition to the linear isomer [5]. Initial PFAS occurrence studies targeted only PFOS and/or PFOA, and without isomer delineation. Research involving additional PFAS has increased as awareness of the numbers of PFAS in the environment, analytical method development, and analytical standard availability have increased. Table 1 provides a classification and acronym summary for the PFAS that have been included in the plant uptake studies reviewed. PFAS in these studies were quantified using liquid chromatography (LC) paired with mass spectrometry (MS), tandem mass spectrometry (MS/MS), high-resolution mass spectrometry (HRMS), or quadrupole time of flight MS (QToF-MS) [46, 47]. Targeted quantification is limited to availability of standards, which currently includes approximately 60 PFAS. Suspect and nontarget screening with advanced MS instrumentation (e.g., QToF-MS) may be used to identify other PFAS including precursors and intermediates in the pathways to PFAAs. Precursor transformation to PFAAs typically involves multiple transformation steps with different degradation rates and some quite stable intermediates. Degradation rates, metabolites, and metabolite yields vary with each PFAS class as well as environmental factors commonly known to affect microbial degradation [48]. For example, aerobic half-lives of fluorotelomer alcohols are $<1$ week with yields to PFOA as high as $40 \%$ whereas aerobic soil 


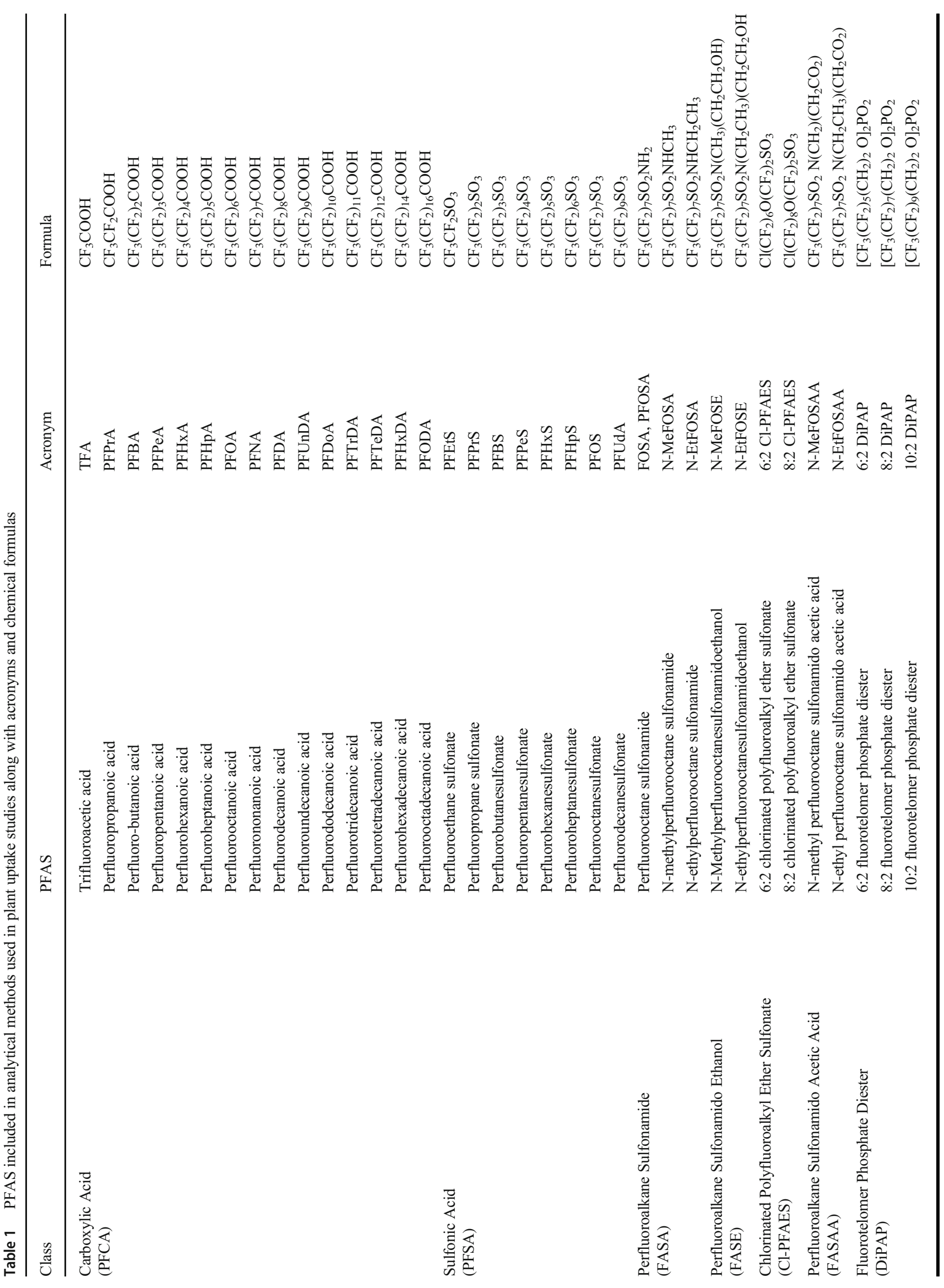




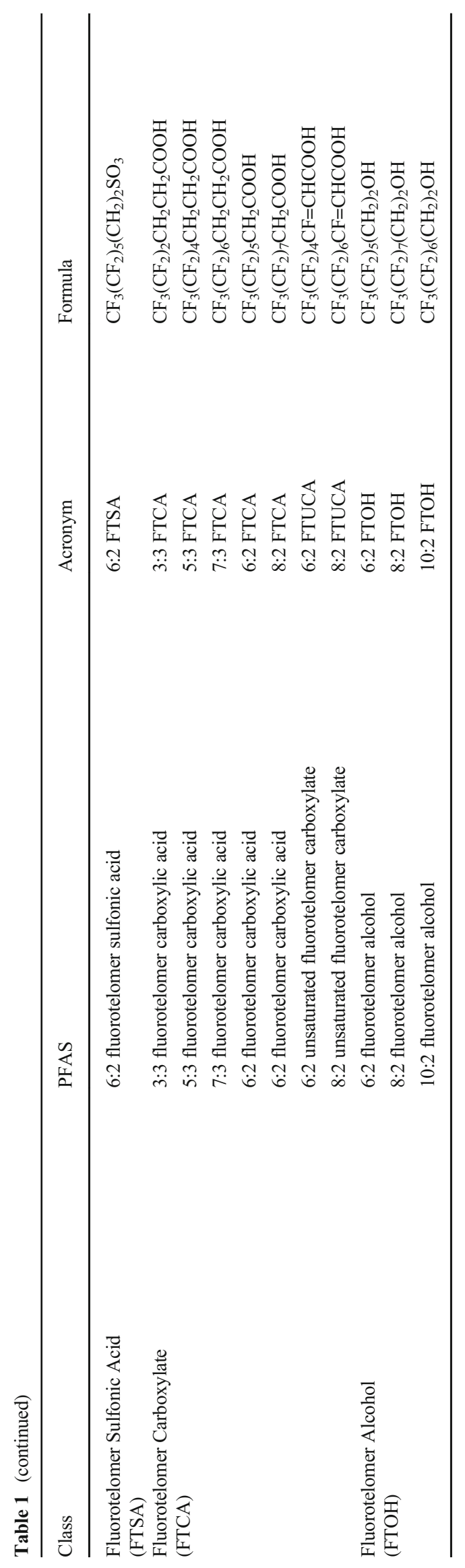

degradation of fluorotelomer sulfonates, which is both a precursor and an intermediate of some larger Scontaining PFAS, is much slower with desulfonation being the rate-limiting step [49].

Other approaches for estimating the contribution of unknown PFAS loads include conducting a fluorine mole balance using bulk organofluorine measurements or chemical assays such as the total oxidizable precursor (TOP) assay, particle-induced gamma-ray emission (PIGE) method, and adsorbable organic fluorine (AOF) or extractible organic fluorine (EOF) paired with combustion ion chromatography (CIC) methods [50]. Understanding the contribution of the unknown PFAS is helpful when making cross-study comparisons between $\sum$ PFAS, $\sum$ PFSAs, and $\sum$ PFCAs in targeted studies, due to variations between media and precursor degradation in temporal studies. For example, the PFOS precursor sulfluramid (active ingredient EtFOSA), which is a pesticide used in the region to control leaf-cutting ants, was proposed as the most likely source of measured PFOS in Brazilian soils (0.020-3.77 ng/g) [24•]. In a carrot uptake study using soil fortified with EtFOSA, temporal generation of FOSAA and FOSA (intermediates to PFOS) and PFOS with yields up to $34 \%$ was attributed to EtFOSA degradation [25]. Likewise, in a wheat uptake study using FOSA-fortified soil, degradation to PFOS was observed in both the soil and the earthworms [51]. A small subset of these now known precursors is starting to be routinely quantified; however, currently, there are still many known precursors that are often not quantified. In addition, there are likely still many unknown and difficult to quantify precursors that may be a significant fraction of the total PFAS present and could serve as a continual source of PFAAs depending on degradation potential and degradation rates. For example, a recent study looking at several Canadian biosolids found two side-chain fluorinated polymer surfactants used in consumer products at higher concentrations than the total for targeted PFAAs [33•]. Therefore, although the list of PFAS typically quantified is likely to expand rapidly over the next few years, PFAS occurrence and potential PFAA reservoir are likely underestimated, especially in, but not limited to, earlier studies.

\section{PFAS Sources and Presence in Soils and Growing Media}

To provide a foundation to discuss PFAS availability to plants in different growing media, typical PFAS types including precursors and concentration ranges are briefly detailed in this section. PFAS have become so ubiquitous in the environment that finding pristine soils is rare. A recent review by Vedagiri et al. [52] of soils in North America with no known PFAS 
point sources found background levels of PFOS and PFOA ranged from 0.018 to $2.55 \mathrm{ng} / \mathrm{g}(n=38$ studies) and 0.059 to $1.84 \mathrm{ng} / \mathrm{g}(n=40)$, respectively. A global survey of 32 PFAS in soils taken from 62 locations with limited to no anthropogenic impact revealed PFAS presence in every sample; longrange transport was identified as the source [53]. Of the data reviewed, 33 samples from North America only reported PFOS and PFOA values. Globally, 2 PFCAs (C6-C14) ranged from 0.03 to $14.3 \mathrm{ng} / \mathrm{g}$, and $\sum$ PFSAs (C6-C10) ranged from < LOD to $3.27 \mathrm{ng} / \mathrm{g}$. Other PFAS quantified are intermediates and precursors in the PFAA degradation pathway including a series of ten FTUCAs and ten FTCAs, which ranged from < LOD to $0.106 \mathrm{ng} / \mathrm{g}$ and $<\mathrm{LOD}$ to $0.048 \mathrm{ng} / \mathrm{g}$ in soils, respectfully. Comparison across the globe indicated that the northern hemisphere (especially Asia and North America) had higher PFAS concentrations than the southern hemisphere, which is consistent with results from previous atmospheric distribution studies and oceanic studies [53].

Biosolids and irrigation waters are the most prominently studied sources of PFAS in agricultural soils. PFAS are found in multiple water resources around the world [52], which when utilized as an irrigation source can lead to higher PFAS loads in soils then global background concentrations. Irrigation with well water, treated wastewater effluent, and surface water is essential to agriculture in many regions, and thus is a source of PFAS to plants that is difficult to avoid. Of 13 PFAS tested in agricultural soils from a Ugandan wetland irrigated with surface water receiving effluent discharged by wastewater treatment plants (WWTPs), PFOS was the most abundant (36-50\% of $\sum$ PFAS, $\left.0.6-3.0 \mathrm{ng} / \mathrm{g} \mathrm{dw}\right)>$ PFOA $(6.2-15 \%, 0.48-0.91 \mathrm{ng} / \mathrm{g} \mathrm{dw})>$ PFHxA $(4.7-18 \% \mathrm{dw}, 0.2-$ $0.5 \mathrm{ng} / \mathrm{g} \mathrm{dw}$ ) [23]. In a South Korean rice paddy irrigated with surface water impacted by effluent from WWTP receiving textile industry waste, the soil contained $\sum$ PFAS ranging from 0.12 to $13.9 \mathrm{ng} / \mathrm{g} \mathrm{dw}$ [54]. Zhang et al. [55] reported $\sum$ PFAAs in irrigated agricultural fields in China ranging from 0.29 to $4.28 \mathrm{ng} / \mathrm{g}$ (mean $1.62 \mathrm{ng} / \mathrm{g}$ ) with PFOA (39\% of $\sum$ PFAAs) > PFDA $(16 \%)>$ PFBA $(9 \%)>$ PFHxA $(7 \%)=$ PFNA $(7 \%)$. In home gardens in the USA irrigated with landfill leachatecontaminated groundwater, several PFAAs, including PFOA (0.11-3.0 ng/g), PFOS (0.57-12.0 ng/g), PFBA (0.04$13.0 \mathrm{ng} / \mathrm{g}$ ), PFPeA (ND-0.57 ng/g), PFHxS (ND$0.24 \mathrm{ng} / \mathrm{g}$ ), and PFHxA (ND-0.66 ng/g), were detected in over $70 \%$ of the soil samples from 20 home gardens [22•]. Comparatively lower concentrations were found in 3 irrigated gardens outside the contaminated zone: PFOS $(0.93-2.1 \mathrm{ng} /$ g), PFOA (0.29-0.54 ng/g), and PFBA (0.073-0.49 ng/g).

Waste-derived soil amendments and fertilizers, including biosolids and composts made from biodegradable solid wastes, are frequently land-applied as an organic matter source that improves soil structure and water-holding capacity as well as a slow-release source of nitrogen and other microand macronutrients [56-58]. Concerns that these waste- derived soil amendments are significant sources of PFAS to the environment have been increasing over the past decade $[27 \bullet, 30,33,35,59,60]$. Biosolids, which are prepared from the sludge produced in the wastewater treatment process, inherently contain higher concentrations of the more sorptive longer perfluoroalkyl chains and larger precursors than the corresponding wastewater effluent. Longer-chain PFAS refer to those that have six or more perfluoroalkyl carbons. Degradation of these precursors throughout the sludge treatment process and after land application can lead to increased concentrations of the shorter-chain PFAAs [61]. PFAS loads to soil from biosolid application depend on the PFAS sources to WWTPs, the PFAS concentrations in the biosolids, and biosolid application rates $[33 \cdot, 62,63]$. Furthermore, given the persistence of PFAS, multiple biosolids applications may result in higher PFAS concentrations [63, 64]. Sepulvado et al. [64] investigated PFAS at a site in Illinois where biosolids were applied over a 3-year period. Various loading rates and soil types were utilized, along with 6 different biosolids that contained a mean $\sum$ PFAS concentration of $433 \mathrm{ng} / \mathrm{g}$. PFOS (80-219 ng/g), MeFOSAA (63-143 ng/g), EtFOSAA (42$72 \mathrm{ng} / \mathrm{g})$, and PFOA(8-68 ng/g) were detected most frequently in biosolid samples [64]. PFAS leaching at the site increased with decreasing carbon chain length, thus greater leaching of short-chain PFAS was observed [64]. While Sepulvado et al. [64] did include known PFAA precursors MeFOSAA and EtFOSAA in their study, other precursors yet to be identified may have been present. For example, in soils from a biosolid-amended field in Ontario, Chu and Letcher [30] found, for the first time, two side-chain fluorinated polymer surfactants (S1 and its shorter-chain replacement S2) from Scotchgard ${ }^{\mathrm{TM}}$ fabric protectors totaling $\sim 240 \mathrm{ng} / \mathrm{g}$ $\mathrm{dw}$, which was one hundred times higher than the total sum of 22 other more typically targeted PFAS [30]. Later, they found these same PFAS in biosolids from numerous wastewater treatment plants in Canada [33॰]. While studies have yet to be conducted to quantify the degradation of these larger PFAS, PFAS used in textiles and leather for stain and water resistance may be a long-term source in domestic wastewater with potential to generate PFAAs.

Most commercially available waste-derived products sold in local or major store chains, which are typically purchased for use in urban and sub-urban gardens, golf courses, and public and homeowner lawns, have been found to contain PFAS. Kim Lazcano et al. [59] found 9.0-181 ng/g of total PFAAs in commercially available municipal biosolid-based products. PFAS are also present in non-biosolid urban waste-derived composts made from compostable paper products, food wastes, and tree and grass clippings. Total PFAAs in organic waste composts ranged from 31 to $75 \mathrm{ng} / \mathrm{g}$ for those containing food packaging with PFAS concentrations being lower in composts of only food and yard wastes $(\leq 18.89 \mathrm{ng} / \mathrm{g})$ $[35,59]$. All these biosolid and non-biosolid waste-derived 
composts contained PFOA and PFOS even though phase out was several years earlier than when these materials were produced. Several PFAS precursors were also detected with the most common being the 6:2 diPAP and 6:2 FTS $[35,59]$. Likewise, total PFAAs up to $80 \mathrm{ng} / \mathrm{g} \mathrm{dw}$ were found in biowaste from biogas production [31]. Overall shorter-chain PFAAs were higher in municipal solid waste- and biowastederived amendments compared to biosolid-based products [31, 35, 59]. Other waste-derived materials used as soil amendments that have not been studied for PFAS occurrence include paper mill wastes [65] which are expected to contain PFAS associated with PFAS-based paper coatings. Other PFAS sources applied to agricultural soils include PFASbased pesticides, e.g., sulfluramid as exemplified already, or pesticides that may contain PFAS in their formulations as an ingredient in the surfactant carrier of which little is known.

PFAS production or use in manufacturing can lead to PFAS additions to agricultural soils through atmospheric deposition and/or contaminating water used for irrigation. Soil samples in agricultural fields located in five cities near fluorochemical manufacturing sites were commonly found to contain PFAS with detection frequency of PFBA $(18.2 \%)>\operatorname{PFOA}(31.8 \%),>\operatorname{PFDA}(11.4 \%)>\operatorname{PFNA}(12.6 \%)$ [66]. Liu et al. [36] reported total PFAS concentrations in agricultural soils of 79.9 to $200 \mathrm{ng} / \mathrm{g}$ and 2.09 to $3.75 \mathrm{ng} / \mathrm{g}$ within $0.3 \mathrm{~km}$ and $10 \mathrm{~km}$, respectively, of a fluorochemical plant. PFOA made up the greatest portion $(83.4 \%$, up to $181 \mathrm{ng} / \mathrm{g}$ ) of the total quantified with the remainder being primarily the shorter-chain PFCAs [36].

Use of AFFFs has led to release of a wide range of both PFAS types and concentrations to the environment. For example, in Australia, 60 different PFAS were detected in AFFF-impacted soil, including novel PFAS identified with nontarget techniques [26]. Several PFSAs, PFCAs, chlorinated perfluoroalkyl sulfonate (Cl-PFSAs), ketone perfluoroalkyl sulfonates, FASA, perfluoroalkyl sulfinates, perfluoroalkyl sulfonamidoethanols, fluorotelomer sulfonates, and perfluoroalkyl sulfoamido amines as well as one fluorotelomer thioamido sulfonate were detected. This exemplifies the need to include nontarget screening in future studies, particularly at, but not limited to, AFFF-impacted sites. High total PFAS concentrations are often observed at fire training sites, e.g., Dauchy et al. [67] reported up to $710,126 \mathrm{ng} / \mathrm{g}$ in surface soils and 300 to $8300 \mathrm{ng} / \mathrm{L}$ in groundwater.

\section{PFAS Sorption and Mobility Characteristics}

PFAS interactions with soil moderate PFAS mobility and plant availability, thus the long-term dynamics of PFAS in agricultural systems. Within a class of PFAS (e.g., PFCAs, PFSAs), PFAS sorption to soils increases with increasing perfluoroalkyl chain length [68]; therefore, leaching and bioavailability increase with decreasing chain length [64, 69]. For a given chain length, sorption tends to be higher for PFSAs compared to PFCAs [68]. Cationic and some zwitterionic PFAS tend to have a high affinity to agricultural soils, since healthy soils typically contain a significant cation exchange capacity $[45,70]$. Although soil organic carbon (OC) generally increases sorption of organic contaminants, in a review by Li et al. [60], no consistent trend was apparent between OC and PFAS sorption by soils across the globe. Although parameters that may affect sorption were not provided in all papers, $\mathrm{Li}$ et al. [60] were able to evaluate trends between sorption, $\mathrm{pH}$, and cation concentrations. They found $\mathrm{pH}$ to be significantly correlated to sorption for only EtFOSAA $(n=10)$, MeFOSAA $(n=10)$, and PFDS $(n=10)$, while a general trend of increasing PFAA sorption with increasing cation concentration and overall salinity was evident [60]. Correlations to other soil properties such as exchange capacities were constrained because property information was most often not reported [60]. Using PFAA sorption data obtained for a single soil and a single concentration but with different solution $\mathrm{pH}$ and cation presence (Al, $\mathrm{Ca}$, and $\mathrm{Na}$ ), Campos Pereira et al. [68] generally observed inverse correlations between OC-normalized sorption coefficients and $\mathrm{pH}$. Both PFAAs and acid functional groups in soil organic matter (SOM) become more anionic with increasing $\mathrm{pH}$, thus lower sorption with higher $\mathrm{pH}$ may be expected for anionic PFAAs. Cation effects were more varied and complicated since their addition can invoke $\mathrm{pH}$ changes as well. Overall, the authors attributed the effects observed to changes in the net charge of organic matter, which can be impacted by $\mathrm{pH}$ as well as cation charge and concentration. They also hypothesized that longer-chain PFAAs preferentially sorb to the humin SOM fraction whereas sorption of the shorter chain was more to humic and fulvic acid domains [68]. Although data were limited, results indicated that different $\mathrm{OM}$ sources (e.g., OM arising from different crop and management strategies including land-applied waste-derived amendments) may alter PFAS retention, thus mobility and plant uptake potential. Factors not considered by Campos Pereira et al. [68] include nonlinear sorption behavior [71] and the effect of cation charge and concentration on PFAA clustering [72].

Inorganic anions can also impact PFAA sorption. Addition of phosphate decreased sorption of PFOS due to site-specific competition with the greatest impact being in soils with low OM content and high ferric oxide content [71]. Given the importance of phosphorus as a nutrient in agricultural systems, further studies on the effect of phosphorus speciation and concentration on sorption of additional PFAS are warranted. Lastly, other sorption mechanisms unique to PFAS as surfactants include the potential for enhanced retention at the air-water interface in the vadose zone [73, 74] (the unsaturated zone of soil above the water table including the root zone). 
In unsaturated soils, air-water partitioning of PFOS [74] and PFOA [73] at higher concentrations typical of AFFF-impacted sites accounted for $32 \%$ and up to $75 \%$ of the retention by soil, respectively. This indicates that rain events that lead to saturation may temporarily mobilize sorbed PFAS. The role of interfacial tension at PFAS concentrations that may be released from typical waste-derived soil amendments versus AFFFs is yet to be determined.

\section{Uptake into Agricultural Plants}

The plant uptake studies reviewed include hydroponic studies $(n=17)$, pot studies $(n=19)$, and field studies $(n=14)$ (Table S1). Table 2 provides a summary of the plant species studied, reported uptake and comparisons between study types for the most commonly studied PFAAs, and the range in number of PFAS that have been included in at least one study for the given species organized by classification. A total of 63 field crops and produce types have been studied with the most studied reported in Table 2. Grains, leaf vegetables, and root vegetables were the most studied plants, with sweet fruits being the least studied. Generally, vegetables and vegetative plant components had higher PFAS concentrations than grains and fruits. In home gardens, floret vegetables had higher concentrations of PFAS than other plant categories [22]. Studies indicate that long-chain PFAAs will be less susceptible to leaching and less likely to transfer from soils to plants or be translocated compared to the shorter-chain replacements which are more water soluble $\left[12,35,75^{\bullet}\right]$. Likewise, precursors can serve as a reservoir of smaller more mobile and bioavailable PFAS (intermediate metabolites and subsequent terminal PFAAs) [51]. The source strength of the precursor reservoir will depend on degradation rates and PFAA yield potential [48], which has not been determined for many precursors especially those more recently identified.

Synthesizing data from plant uptake studies can be challenging due to reported differences between plant species, within plant species (different cultivars), and within the different plant components (root, shoot, leaves, fruit) [42•, 82, 92•], as well if data are reported on a wet or dry weight basis. To compare between treatments and different systems, several ratios have been utilized including the root concentration factor (RCF, ratio of root to soil concentration), translocation factor (TF, ratio of shoot to root concentration) or sometimes called the foliage to root concentration ratios (FRCFs), shoot concentration factor (SCF, ratio of shoot to the growing media), and bioconcentration factor (BCF, ratio of the plant to growing media). In addition, a transpiration stream concentration factor (TSCF) can be used to describe translocation of PFAS via the transpiration stream; however, TSCF is not highly reported and is better suited to hydroponic studies; plants grown in soil require a porewater analysis to calculate TSCF [102•].
In studies using different ratios of PFAS between compartments in various plant systems, the PFAS characteristic appears to be the single most consistent factor affecting TFs and RCFs [20, 36, 62, 75• 74-76, 77•, 79-81, 102•, 103, 104], which allots some insight into uptake mechanism. RCFs generally increased with increasing chain length and were greater for PFSAs compared to PFCAs of similar chain length [76, $80,102 \cdot, 104]$, whereas TFs generally increased with decreasing chain length $[20,36,62,75 \cdot, 76,79,80]$. However, there are exceptions to these general trends attributed to plant-specific mechanisms to be discussed in the mechanism section $\left[91,105^{\bullet}\right]$. For a given PFAS, there are also notable trends with PFAS concentrations in the growing media. Current trends described in the literature indicate that root uptake concentrations increase with increasing PFAS concentrations $[82,91,96]$. This leads to relatively constant RCF values for given PFAS unless sorption to tissues reaches a maximum (e.g., nonlinear sorption to tissues) in which case the RCFs may decrease [91]. Across many species, shortchain PFAAs readily uptake and translocate throughout the plants $[36,42 \cdot, 75 \bullet, 79,104]$, thus they tend to have higher TFs than longer chain. Short-chain PFAAs translocated to edible portions of crops more often than long-chain PFAAs [66], partially because short-chain PFAS sorb less to soils [106] and thus are more bioavailable [22•, 104, 107]. Also, it is plausible that with smaller size PFAS, plant root barriers may have a reduced impact on restricting their translocation [75•] as will be discussed in regard to plant uptake mechanisms.

Study type and design will affect PFAS bioavailability, the contact period during which the plant can uptake PFAS and/or PFAS effects on the plant. In hydroponic systems, overall PFAS availability is high compared to soil since it is not moderated by sorption; however, the root surface area where uptake occurs can be reduced in a hydroponic system. For example, red chicory root development in hydroponic systems was reduced; thus, uptake surface area decreased compared to chicory grown in soil [102•]. Most studies, particularly in pot and hydroponic studies, invoke PFAS treatments to seedlings (germination occurs in a different environment); thus, potential effects on germination and early growth are missed. Field studies often include impacts on germination since seeds are planted rather than seedlings and have additional variables that can impact PFAS availability for plant uptake such as potential for compounds to leach out of the root zone and climate variability. Also in most pot studies, leaching is minimized or prevented; thus, short-chain PFAS remain in the root zone unlike what is likely to occur in the field. For example, decreases were reported in short-chain PFAS concentrations in the soil profile throughout a growing season due to leaching $[64,106]$, whereas in a pot study short-chain PFAS became enriched in the bottom layers of the pot compared to the longer-chain PFAS and remained accessible for 


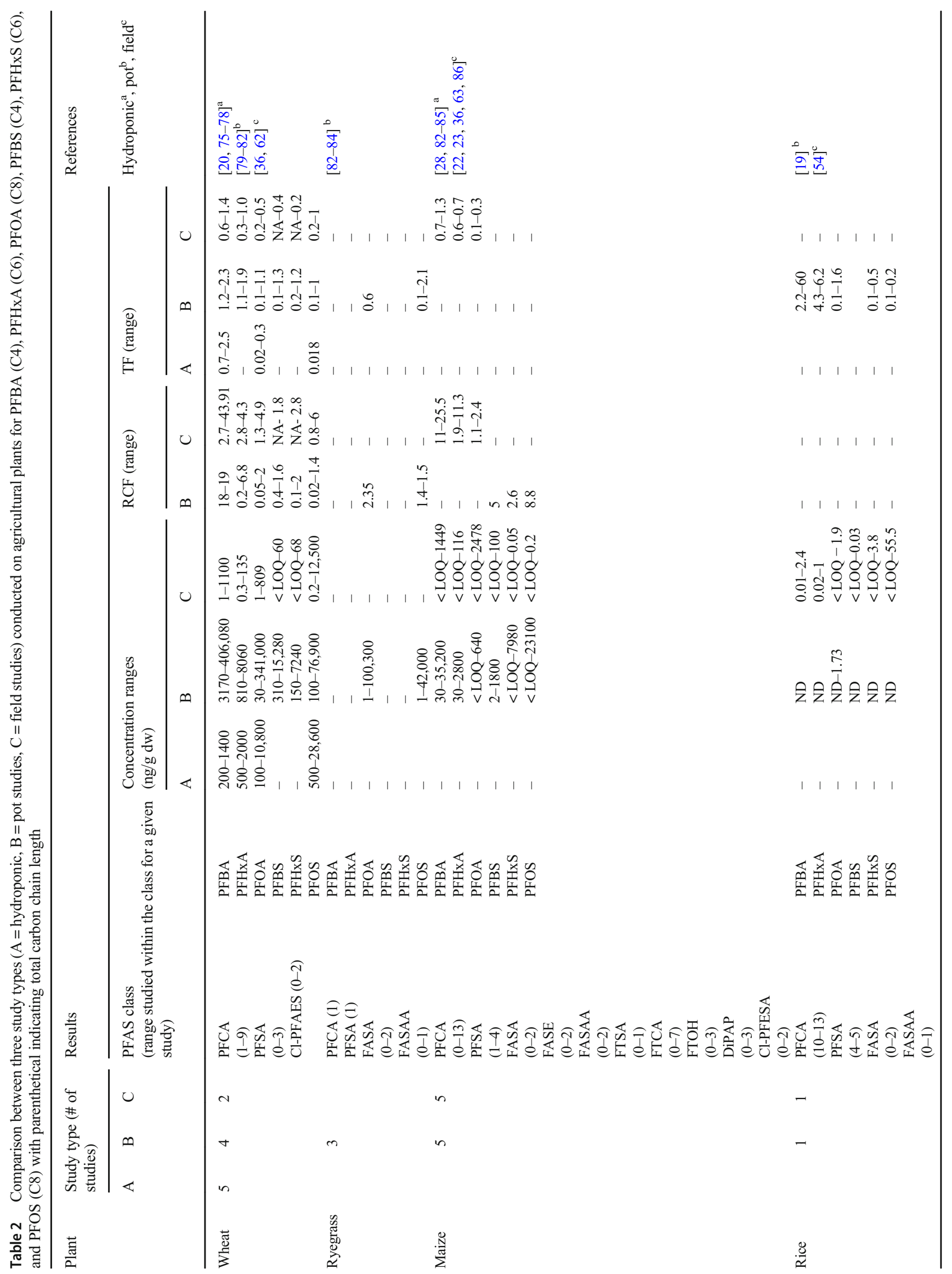




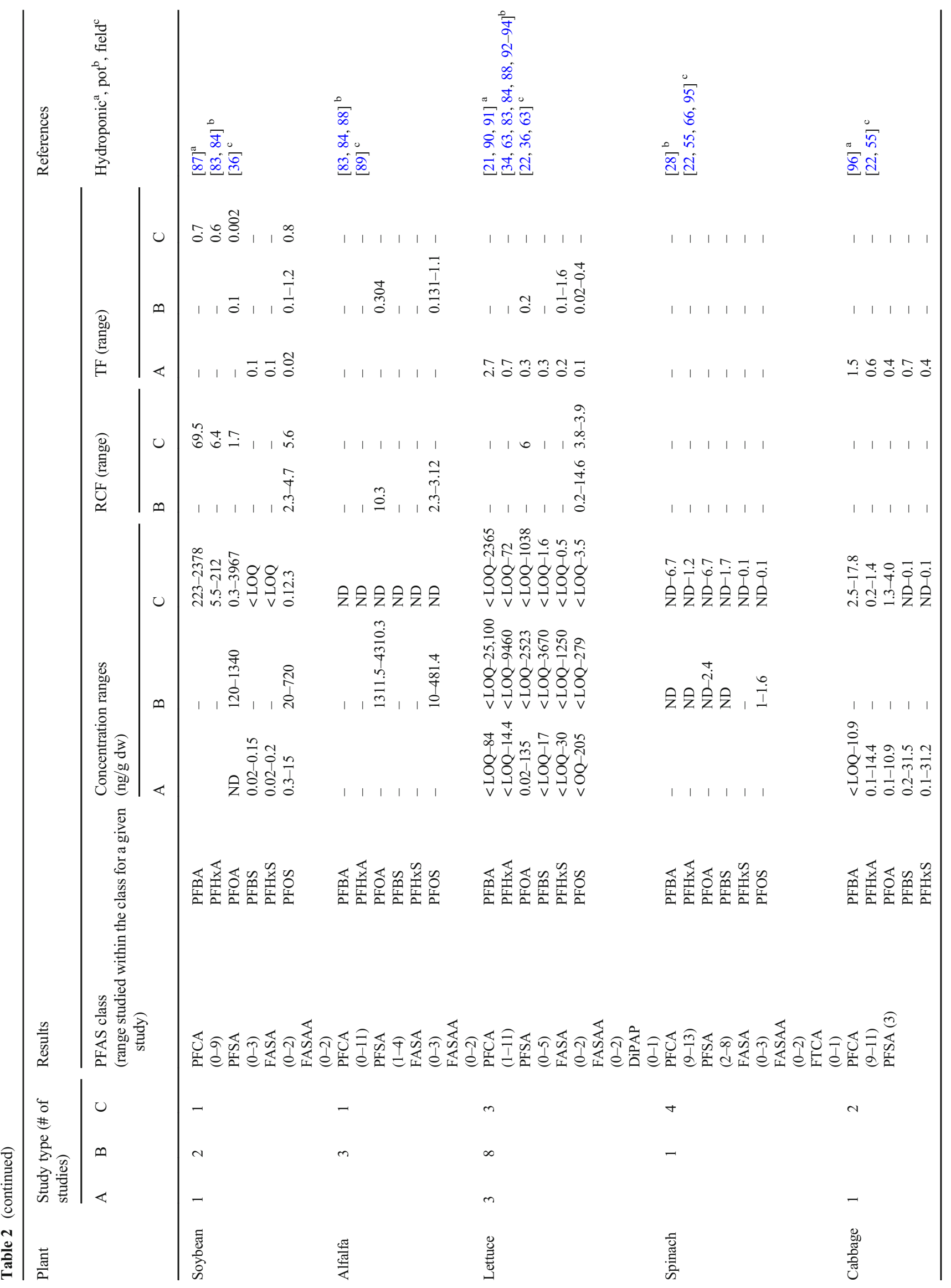




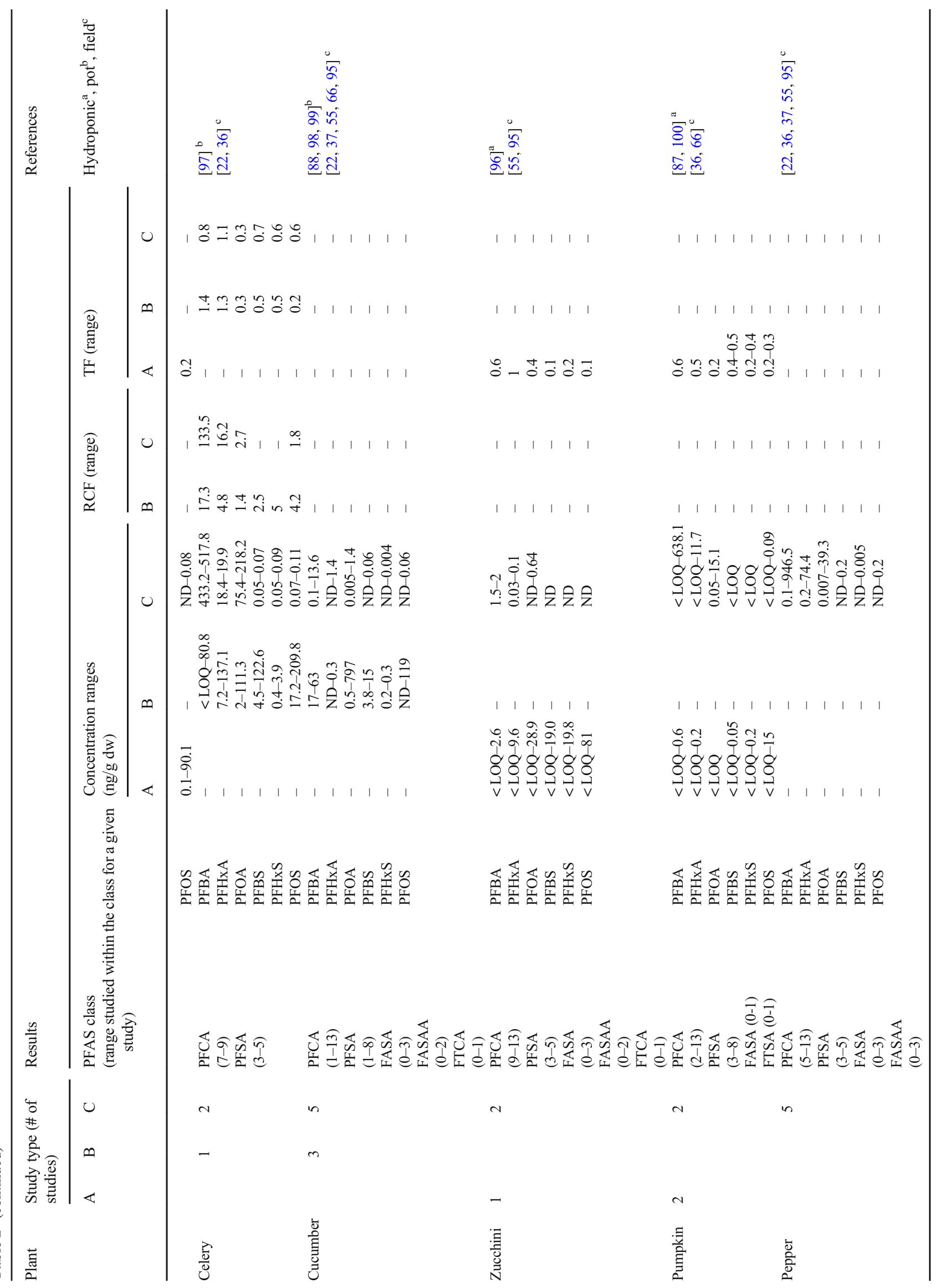




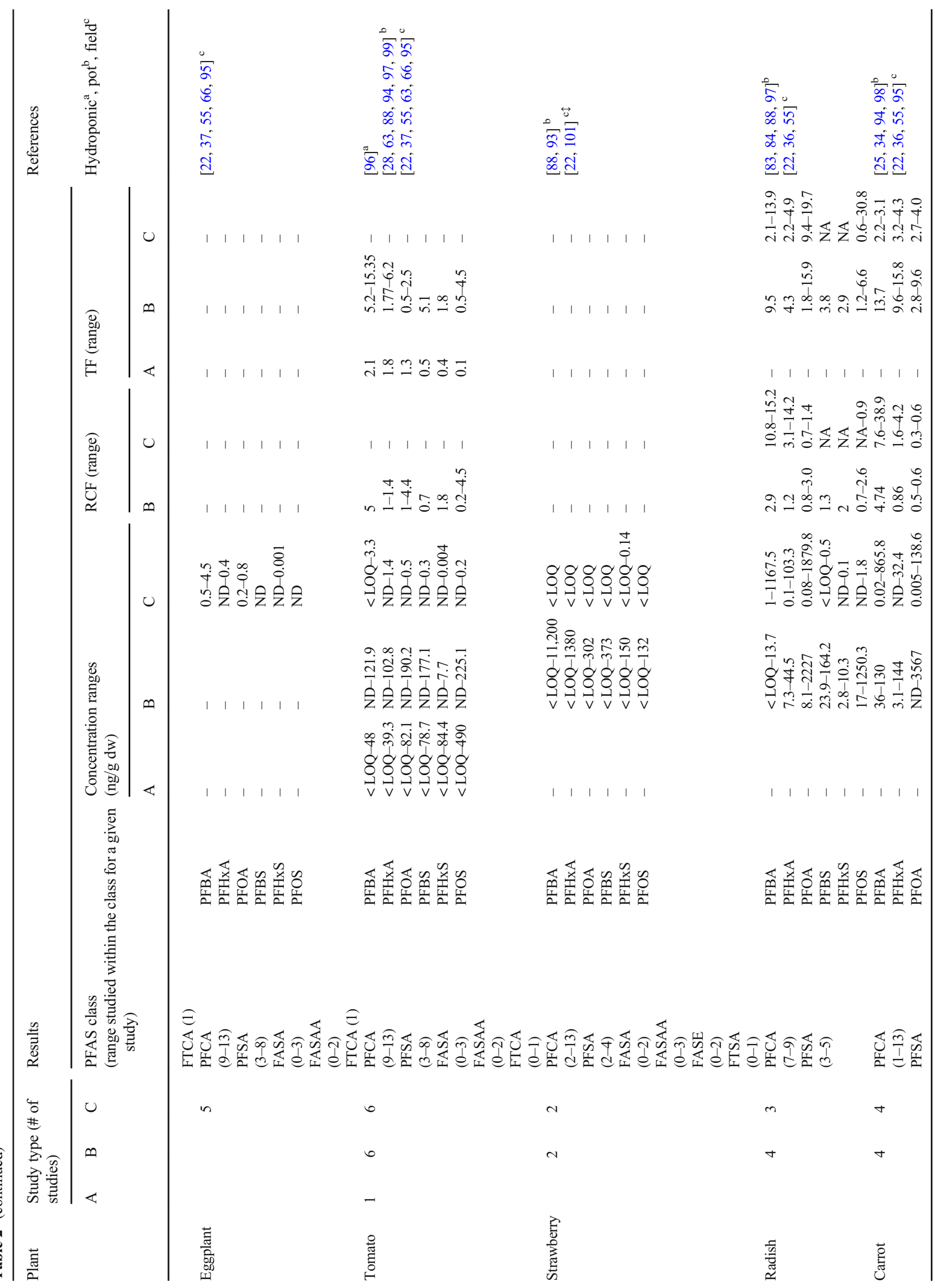




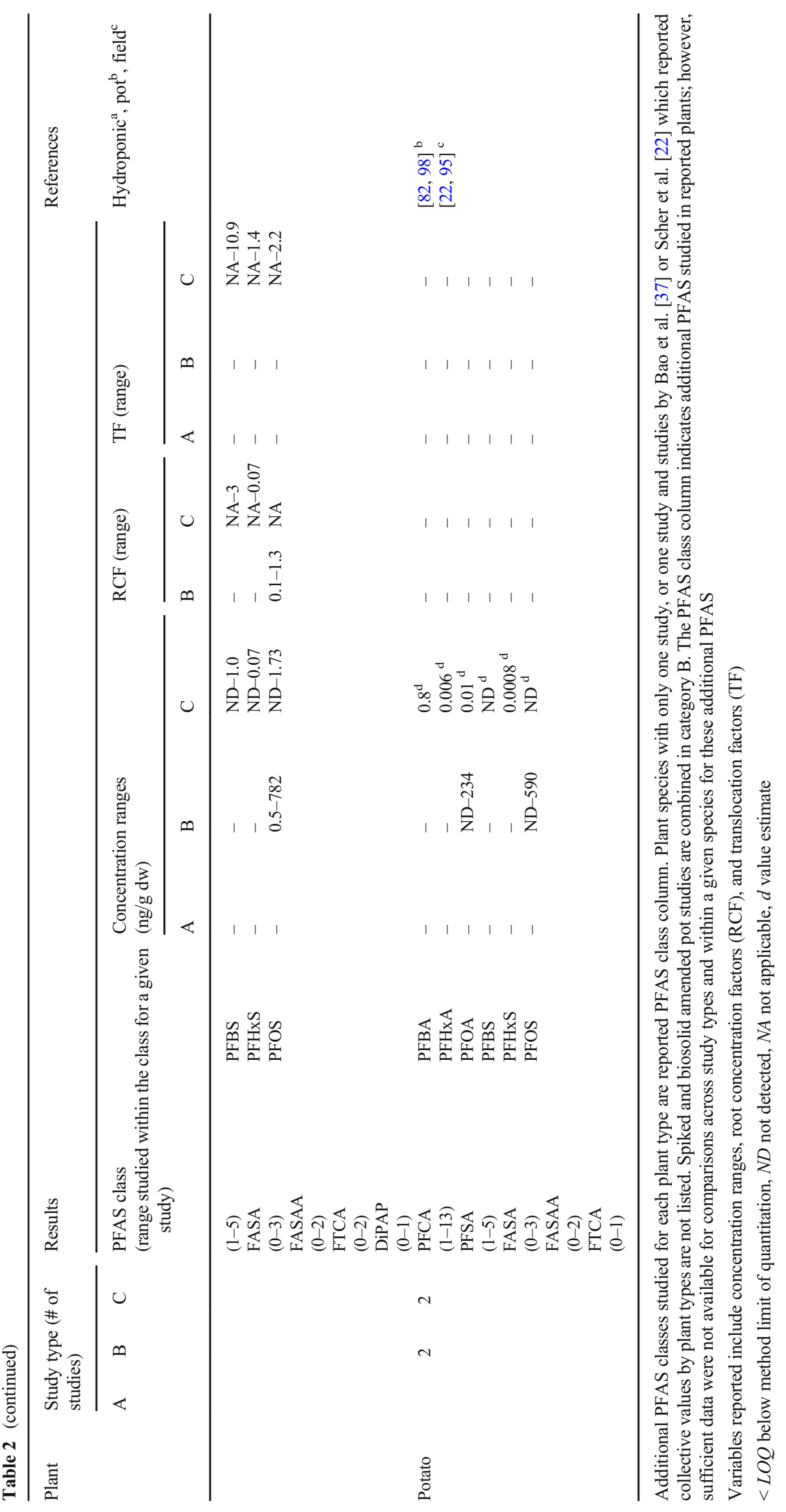


plant uptake [104]. Thus, study design must be considered when interpreting plant uptake magnitudes and mechanisms.

Field studies on plant uptake of PFAS and the number of different PFAS analyzed have increased in recent years; eleven field studies are summarized here that were not previously reviewed [42•]. Two field studies noted a correlation between the level of short-chain PFAS taken up by crops and the volume of PFAS-contaminated irrigation water used [22•, 55]. For example, $60 \%$ of the variability in PFBA concentrations in home garden-grown produce was accounted for by differences in the volume of PFAS-contaminated water used to irrigate the gardens [22•]. For a variety of lab and greenhouse designed studies, PFCAs have been shown to translocate from plant roots to shoots more readily than PFSAs. However, field-scale translocation and soil-root transfer data are sparse; sampling rarely includes harvest of non-edible crop components. In cases where soil-root transfer was evaluated, PFAS contributions from atmospheric deposition confounded accurate $\mathrm{TF}$ and $\mathrm{BCF}$ comparisons, especially in plants grown near fluorochemical manufacturing. For example, field-grown lettuce at a site $0.3 \mathrm{~km}$ from fluorochemical manufacturing had up to $2370 \mathrm{ng} / \mathrm{g}$ PFBA and $1040 \mathrm{ng} / \mathrm{g}$ PFOA in lettuce and only $5 \mathrm{ng} / \mathrm{g}$ PFBA and $90 \mathrm{ng} / \mathrm{g}$ PFOA in soil [36], whereas lower concentrations in lettuce (no more than $270 \mathrm{ng} / \mathrm{g}$ PFBA and $200 \mathrm{ng} / \mathrm{g}$ PFOA) were observed in pot studies grown at similar soil PFAS concentrations (6 ng/g PFBA and $80 \mathrm{ng} / \mathrm{g}$ PFOA in soil at the time of harvest) [63]. Though costly, future field study designs should target inclusion of data that will enable estimations of BCFs and TFs to different plant domains to better ascertain uptake mechanisms and predict risks associated with accumulation in both human and animal edible components.

Studies that include additional PFAS classes as well as precursor and precursor degradation intermediates in plant studies are limited. A single study that included Cl-PFAESs found that the TF in wheat of 6:2 Cl-PFAES (a PFOS replacement) was similar to that of PFOS, while 8:2 Cl-PFAES had a lower TF, indicating that chain length effects occur within other PFAS classes similar to those observed for PFCAs and PFSAs [77•]. A single study addressed uptake of ultra-shortchain PFCAs (C2 and C3) [75•]. This study was with hydroponically cultivated wheat in which they found high uptake of C2 and C3 PFCAs into the roots and shoots due to multiple uptake mechanisms [75•]. As previously noted, EtFOSAfortified soils produced a series of degradation products (FOSAA, FOSA, and PFOS) which increased when growing carrots [25]. Both the intermediate FOSA and terminal metabolite PFOS were found on the carrot peel as well as transported into the leaves along with small amounts into the carrot core whereas the precursor EtFOSA remained in the soil with only small amounts found on the peel [25]. Zhao et al. [108] exposed hydroponically cultivated wheat, soybean, and pumpkin to EtFOSA $(1 \mathrm{mmol} / \mathrm{mL})$ and proposed in vivo transformation of EtFOSA to FOSAA, FOSA, and PFOS in solution by microbes and further metabolic degradation in plant tissue to PFOS, PFHxS, and PFBS. Impurities in the EtFOSA standard lead to initial PFOS concentrations in the incubation solution; however, PFOS concentrations significantly increased in the presence of plant roots and associated microbes [108]. Similar results were observed for wheat with FOSA-fortified soils [51] and hydroponically grown soybeans and pumpkin [87] except that additional shorter-chain PFSAs (PFHxS and PFBS) were observed, particularly in the roots with some in the shoots, albeit at much lower concentrations than PFOS. PFOS is a known microbial degradation product of FOSA while PFBS and PFHxS are not [34]. The authors attributed the formation of short-chain PFSAs to a unique metabolic pathway. However, there are several noteworthy points to consider. First, the FOSA used was a technical grade (90-92\% purity) with 8 mol\% PFOS. Analysis targeted only FOSA, PFOS, and shorter-chain PFSAs and PFCAs; therefore, other impurities would have been missed such as shorter perfluoroalkyl chain sulfonamides, which would lead to PFSA degradation products of the corresponding chain length. In addition, in the case of wheat grown in both systems, higher levels of these short chains were found when grown in soils where microbial degradation would be higher [51]. Also in the hydroponic systems for soybean and pumpkin, small amounts of both PFBS and PFHxS were found in the plant controls (no FOSA added) [87]. Lastly, in order to form PFBS and PFHxS from FOSA, cleavage to produce a shorter fluorinated alkyl chain with reattachment of either a fluorine atom (if $\mathrm{C}-\mathrm{C}$ cleavage occurred) or a sulfonate group (if C-S cleavage occurred) would have had to happen, which seems thermodynamically unlikely. Therefore, although the authors propose that production of PFBS and PFHxS from FOSA indicates a unique plant-mediated metabolism, it is much more plausible that these results are due to impurities in the technical FOSA used, for which additional support using oxidative stress measures was provided [87]. Enhanced degradation in the presence of plants and formation of additional metabolites relative to what is known to occur in microbially active soils have also been shown for 6:2 FTSA [87] and 8:2 diPAP [34]. Carrots enhanced 8:2 diPAP degradation and yielded additional PFCAs compared to what occurred in soil-only controls as well as what was observed with lettuce [34]. Whereas acid metabolites translocated, 8:2 diPAP remained primarily in plant portions in contact with the soil (e.g., carrot, lettuce heart) [34]. Therefore, plant-mediated degradation of $8: 2$ diPAP was likely due to carrot exudates rather than degradation within the plant. In 6:2 FTSA exposure to hydroponically grown pumpkin, series of PFCAs (C2-C7) were produced with the $\mathrm{C} 2$ and $\mathrm{C} 3$ acids not present in root exudates controls; therefore, the authors concluded some 6:2 FTSA biotransformation was occurring within the plant. Such complexities can complicate interpretation of PFAS-specific uptake. 


\section{Plant Uptake Mechanisms}

Plant mechanisms involved in chemical uptake are plant-specific, but must first involve initial transfer to the root and adsorption to apoplastic plant tissue followed by translocation through the xylem in the central vasculature to the shoot and remainder of the plant. It is widely accepted that the Casparian strip, which is located in the root endodermis and made up of lignified structures that regulate water and mineral uptake by the roots, also serves to constrain translocation of contaminants from roots to the central vasculature, thus the rest of the plant [109]. The Casparian strip prevents passive transport of compounds across the endodermis, by sealing the nonliving spaces between cells and cell membranes (apoplast) [110]. The suberin lamella is an additional selective barrier that is formed in some plants by covering the endodermal cells with the hydrophobic polymer suberin [109].

Trends discussed in PFAS plant uptake studies are consistent with this hypothesis that the Casparian strip constrains translocation of long-chain PFCAs, PFSAs, FOSAs, and ClPFAESs, thus resulting in TF $<1$ for these PFAS. Felizeter et al. [91] hypothesized that transfer of long-chain PFAS was inhibited by the Casparian strip while the more soluble shorter chains were transported with water into the foliage by comparing RCF, FRCF, and TSCF values for C4-C14 PFCAs and C4-C8 PFSAs in hydroponic studies with lettuce and in light of sorption to root isotherms. They showed that both RCFs and TSCFs had U-shaped curves with the minimum occurring with C7 PFCA while FRCFs consistently decreased with increasing chain length. They also showed that sorption to root isotherms were only linear for C4-C6 PFCAs and PFBS while all longer-chain PFAS exhibited nonlinear isotherms. Findings from hydroponic studies may not transfer well to studies with soils due to the strong chain-length-dependent interactions of PFAS with soils, thus affecting RCFs and subsequent translocation. Müller et al. [105•] further investigated this U-shaped curve phenomenon by measuring uptake, depuration, and translocation kinetics for C4-C10 PFAAs in hydroponically cultivated Arabidopsis thaliana in which they evaluated uptake kinetics to root and shoot independently. They also evaluated sorption to dead roots which they used to calculate sorption normalized concentration factors (SNCFs) to better differentiate between physical adsorption and active uptake. They observed preferential uptake of PFBA followed by slow and incomplete depuration. Thus, they proposed a 2-compartment uptake process occurs in which PFBA uptake by the root symplast is reversible whereas uptake by one or more compartments is not reversible, which may involve the central vasculature and/or organelles and be influenced by active transport from the roots [105 ${ }^{\circ}$. Other hydroponic studies with wheat also saw enhanced translocation of shorter-chain PFBA compared to the longer-chain PFAAs [75• 78]. Different transport inhibitors were used to elucidate active transport mechanisms in hydroponically grown wheat exposed to $\mathrm{C} 2-\mathrm{C} 8$ PFAAs [75•] and in an Asian wetland plant (Alisma orientale) exposed to PFOA and PFOS [111]. Both studies observed Michaelis-Menten type uptake behavior and when coupled to the effects of inhibitors concluded that PFAA uptake is an energy-dependent active uptake process mediated by carrier proteins. Depending on the specific PFAA and plant species, transport of these carriers could involve anion channels and/or aquaporin channels [75•, 111]. For chicory grown hydroponically, Gredelj et al. [102•] did not observe a pronounced U-shape trend in PFAA (C4-C10) uptake behavior, which was attributed to using higher PFAA exposure concentrations than comparable studies [91, 105•]. Gredelj et al. [102•, 104] also exemplified that chain-length-dependent uptake patterns observed hydroponically may not compare directly to soils grown in soils due to PFAS-soil interactions.

Several studies indicate that root proteins and lipids may influence uptake and bioaccumulation of PFAS in plant tissues [76, 83, 84, 108, 111]. Wen et al. [83, 84] found positive correlations between PFOS and PFOA RCFs and root protein content [83] as well as between TFs and shoot to root protein ratios [84] across seven plant species (alfalfa, lettuce, maize, mung bean, radish, ryegrass, and soybean). Likewise for the same plants, Wen et al. [83] found that although root protein content could account for $55 \%$ of the variations in N-EtFOSAA plant concentrations, when combined with lipid content, $85 \%$ of the variation across species was predicted. This was in contrast to PFOS and PFOA in which RCFs were negatively correlated to lipid content. In hydroponic studies, H. Zhao et al. [76] attributed increasing root accumulation with increasing PFCA chain length to sorption to root lipids or membrane proteins resulting in lower translocation of the longer-chain PFCAs (e.g., PFDoA) compared to the shorter-chain PFCAs. Zhao et al. [108] found that RCFs for N-EtFOSA increased with increasing root lipid content of hydroponically grown pumpkin, wheat, and soybean. Wang et al. [111] demonstrated that PFOS and PFOA partitioned differently into the subcellular plant components of the hydroponically grown wetland plant Alisma orientale, with PFOA residing primarily in the watersoluble fractions of stems, roots, and leaves and PFOS residing primarily in cell walls of roots and leaves and the water-soluble fraction of stems. PFOA and PFOS increased in the cell walls (anionic) and organelles (15-30\% lipid) of roots, stems, and leaves with time, and reached an approximate equilibrium after 8 days of exposure [111]. When plants were transplanted into new PFAS-free culture solutions, approximately $80 \%$ of PFAS originally taken up was released [111]. These results exemplify that PFAS properties impact uptake to various plant components as well as differences in the subcellular distribution within a plant component.

Contaminants other than PFAS can invoke responses by the Casparian strip and suberin lamellae. For example, maize 
roots responded to $\mathrm{Cd}$ exposure by developing suberin lamella, which along with the Casparian strip can inhibit the translocation of $\mathrm{Cd}$ and other contaminants to the $\mathrm{xy}$ lem and the remainder of the plant [112]. Cocontamination of PFOS or PFOA with $\mathrm{Cd}$ decreased the bioaccumulation of these PFAAs in both wheat and rapeseed; however, the PFAA TFs decreased in wheat only and increased in rapeseed. Interestingly, both the bioaccumulation and TFs of $\mathrm{Cd}$ were increased in both plant types in the presence of these PFAAs [81]. Although the authors hypothesized that the cause of co-contamination effects was due to impacts on sorption to soil, thus soil solution concentrations, this is not well supported given the inconsistent data trends. It is more likely that $\mathrm{Cd}$ invoked changes in the plant. Wang et al. [113] observed an increased presence of suberin lamella or inactivation of aquaporin channels in response to $\mathrm{Cd}$, which may also decrease PFAS translocation [81]. Additionally, potential PFAS-induced damage to the barriers in root structure at high concentrations $(200 \mathrm{mg} / \mathrm{L})$ [78] may allow for increased uptake. Therefore, future studies should consider plant properties that may impact PFAS uptake in addition to sorption dynamics.

Identifying and differentiating PFAS source contributions especially in field studies can be difficult as previously noted. PFAS in irrigation water are readily bioavailable for plant uptake, as demonstrated by Gredelj et al. [104] who showed chicory irrigated with PFAAcontaining water having an increased uptake of longchain PFAAs into the edible heads whereas PFAA soil concentration had a stronger impact on PFAA root concentrations. Seo et al. [114] attributed higher concentrations in plants than expected from soil transfer alone to atmospheric deposition [36]. Seo et al. [114] showed that PFCAs, neutral PFAS, and PFBS commonly partition to the gas phase, while PFOS tends to partition onto airborne particles. Gaseous uptake by tree bark from multiple species in China was identified as the main uptake mechanism for short-chain PFAS, which associated well with high lipid content [115]. In contrast, the presence of long-chain PFAS was attributed to airborne particles being trapped in bark fissures given the lower concentrations in the smooth bark species [115]. The influence of particles and surface texture on PFAS concentrations may also be responsible for higher PFAS concentrations in potato peel than flesh [42•]. For example, recent work showed the presence of PFAS-containing soil mineral derived micron-sized particles on the surface of potatoes even after washing [95]. Therefore, while field studies are critical to bounding PFAS occurrence levels in plants, the multiple variables and variations that exist in fieldscale studies confound data interpretation targeted at understanding uptake mechanisms.

\section{Metabolic Responses and Phytotoxicity}

PFAS presence and uptake can elicit a metabolic response in plants $[21,75 \cdot 100,116]$ which may include chemical modification, conjugation, and compartmentation. Superoxide dismutase (SOD), peroxidase (POD), catalase (CAT), glutathione (GSH), glutathione-S-transferase (GST), cytochromes P450 (CYP450), and malondialdehyde (MDA) are enzymes and metabolites that collectively serve as a defense against damage from superoxide radicals and reactive oxygen species (ROS) by preventing their formation or destroying those formed. PFAS exposure induces plant responses including enzymatic activity $[78,81,87,100,103,116]$ and metabolite production $[21,90]$ that may play a role in reducing phytotoxic impacts of PFAS within plants and/or promote in vivo degradation $[87,100]$.

Metabolic and phytotoxic responses were reported in crops and produce. Co-exposure of PFOS and PFOA caused several inorganic plant elements ( $\mathrm{Na}, \mathrm{Mg}, \mathrm{Cu}, \mathrm{Fe}, \mathrm{Ca}, \mathrm{Mo}$, and $\mathrm{K}$ ) to decrease in lettuce leaves while $\mathrm{Zn}$ increased, which may be due to ROS-induced ion channel leakage [21]. Also in lettuce, PFOS and PFOA altered amino acid metabolites, dipeptides, fatty acids, lipids, phytol, purine nucleosides, phenolic antioxidants, and flavonoids, as a result of stress responses to DNA injury, photosynthesis inhibition, and impact to energy metabolism [90]. PFAS exposure significantly increased chlorophyll, MDA, and POD, but slightly decreased SOD in rapeseed [81]. Co-contamination with $\mathrm{Cd}$ led to PFAS stress responses including decreased urease activity, POD activity, and biomass in rapeseed. In wheat, chlorophyll and MDA inhibition occurred [81]. Also, wheat shoot and root biomass decreased at higher PFAA exposure concentrations (2000 ng/ g) while root biomass increased at lower exposure concentrations $(200 \mathrm{ng} / \mathrm{g})$ [79]. Additionally in wheat, exposures of PFOS at higher concentrations $(100-200,000 \mu \mathrm{g} / \mathrm{L})$ invoked changes in chlorophyll, protein synthesis, growth, SOD, and POD [78]. Chlorophyll $a$ and chlorophyll $b$ increased with exposure to long-chain PFAAs while exposure to shortchain PFAAs led to decreases in chlorophyll $a$ [79]. Pumpkin and soybean exposure to FOSA increased SOD (soybean 19.2-30.8\%, pumpkin 39.2-92.8\%) and POD (soybean $19.2-20.7 \%$, pumpkin $21.1-37.6 \%$ ), likely in response to increased production of ROS [87]. GST and CYP450 also increased with FOSA exposure. Both enzymes are known to play a role in detoxification of contaminants, and thus may have also played a role in plant-mediated FOSA degradation [87]. CYP450 activity increased in pumpkin exposed to $6: 2$ FTSA and when CYP450 activity was reduced by addition of a CYP450 oxidation inhibitor (1-aminobenzotriazole), PFCA metabolites from 6:2 FTSA degradation decreased, supporting plant-mediated biotransformation [100]. Thus, metabolic responses may lead to some oxidative degradation of PFAS, which will be plant and PFAS dependent. However, stress 
responses at the field-scale when irrigating fields or land applying waste-derived fertilizers have not been reported or observed. This is likely due to environmental concentrations typically being lower than those used in lab-based studies, the positive attributes of the amendments to the plants, and their ability to compensate for chemical-induced stress.

\section{Conclusions and Data Gaps}

The PFAS list previously considered to be of interest in soilplant transfer studies has expanded from select PFAAs (mainly PFOS, PFOA, PFBA, and PFBS) to include PFAS precursors, additional PFAAs, and additional PFAS classes (FASAs, Cl-PFAESs, FASAAs, diPAPs, FTSAs, and FTCAs). Of the PFAS discussed, side-chain fluorinated polymer surfactants, diPAPs, FASAAs, and FTSAs, were identified in wastederived fertilizers or fields treated with waste-derived fertilizers. Cl-PFAESs should also be considered, especially in China $[12,77]$. Future field studies on plant accumulation would benefit from including either nontarget PFAS screening and/or utilizing non-specific tests to better evaluate the level of precursors present that may serve as a PFAA reservoir. Degradation rates and pathways (intermediates on the way to PFAAs) in agriculturally relevant soils and conditions are lacking for many precursors and those for recently identified are completely unknown [30,33•]. Such studies are needed to elucidate the true potential for these precursors to contribute to PFAS intermediates and PFAAs becoming available in the root zone for uptake during the life of the plant. Field studies should also expand upon the number of PFAS quantified as increasingly more standards are becoming available. Future studies on PFAS in agricultural soils in both greenhouse and field studies should include sufficient details on soil and soil amendment properties that can influence PFAS mobility, and thus plant availability [60].

Land application of PFAS-containing media results in plant uptake of short-chain PFAS into plant components that are consumed by humans, utilized as fodder, or land-applied. Long-chain compounds typically sorb to or are taken up into plant roots and largely remain in the roots while short-chain compounds have a higher propensity to translocate into plant shoots. Uptake varied between species and within species and was associated with different plant properties including root lipids and proteins. However, more research is needed to make further inferences on the effects of plant characteristics on uptake. Uptake was shown to be an active carrier proteinmediated process in wheat, which contrasts with frequently cited passive transport processes that are constrained by the Casparian strip. Plant uptake depends on how long PFAS reside in the root zone and on PFAS concentrations. Therefore, the use of high concentrations and growing conditions that minimize leaching could explain why plants grown in pot studies generally have higher concentrations of shortchain PFAS than have been observed in field studies. However, when plants are grown in fields close to fluorochemical manufacturing plants, higher concentrations than predicted from PFAS concentrations in soils may be observed due to atmospheric deposition or irrigation with PFAScontaminated water. Likewise, comparisons made between hydroponic and soil-based studies must take into consideration the impacts of soil-based sorption, air-water interface sorption variability, porewater available compounds in soil, and morphological growth differences (root structure and surface area). Lastly, in some cases, plant enzymes were found to enhance degradation rates of precursors and increase the yields of the more bioavailable PFAAs.

Knowledge on mechanisms of soil-plant transfer, phytotoxicity, and PFAS metabolism in plants is growing and can inform future decision-making regarding cultivation on PFAS-laden soils. Similar to how lower PFAS levels are found in agricultural fields than pot studies, phytotoxic effects were observed at exposure concentrations that are generally considerably much higher than those observed in field studies. Risk of PFAS exposure from plant uptake is multifaceted [38] and encompasses not only plants that are directly consumed, but also through the food web (e.g., bioaccumulation in livestock feeding on PFAS contaminated water, forage, and feed) [117]. Field studies that demonstrate plant uptake, fate of PFAS, and risks associated with land-applied media containing PFAS are needed to inform farmers, landowners, and policymakers on how farming practices will impact the food supply chain.

Future studies should aim to:

- Investigate paper mill waste, industrial byproducts, recycled water, and pesticides as potential sources of PFAS in agricultural systems and their impact on source water in agricultural operations

- Conduct additional field studies, particularly those involving land application of typical waste-derived fertilizers or treated effluent

- Include a larger suite of PFAS for quantification consistent with current knowledge as well as analytical approaches that identify allow insight into additional PFAS including precursors that may serve as a long-term release reservoir of more mobile PFAS

- Investigate soil-plant transfer of replacements compounds, e.g., GenX, ADONA, and others as they become known

- Include more realistic PFAS concentrations in studies designed to improve our understanding of plant-specific uptake mechanisms and plant responses to PFAS exposure

- Include studies that improve our ability to quantify the role of plant enzymes on enhanced precursor degradation in the rhizosphere and within the plant 
Supplementary Information The online version contains supplementary material available at https://doi.org/10.1007/s40726-020-00168-y.

Funding This project was supported in part by the USDA National Institute of Food and Agriculture Hatch Funds Accession No. 1006516 a Purdue Andrews PhD Fellowship, and the Hampton Roads Sanitation District, Virginia Beach, VA.

\section{Compliance with Ethical Standards}

Conflict of Interest On behalf of all authors, the corresponding author states that there is no conflict of interest.

Human and Animal Rights and Informed Consent This article does not contain any studies with human or animal subjects performed by any of the authors.Supplementary Information The online version contains supplementary material available at https://doi.org/10.1007/s40726-02000168-y.

Open Access This article is licensed under a Creative Commons Attribution 4.0 International License, which permits use, sharing, adaptation, distribution and reproduction in any medium or format, as long as you give appropriate credit to the original author(s) and the source, provide a link to the Creative Commons licence, and indicate if changes were made. The images or other third party material in this article are included in the article's Creative Commons licence, unless indicated otherwise in a credit line to the material. If material is not included in the article's Creative Commons licence and your intended use is not permitted by statutory regulation or exceeds the permitted use, you will need to obtain permission directly from the copyright holder. To view a copy of this licence, visit http://creativecommons.org/licenses/by/4.0/.

\section{References}

Papers of particular interest, published recently, have been

highlighted as:

- Of importance

•- Of major importance

1. Bečanová J, Melymuk L, Vojta Š, Komprdová K, Klánová J. Screening for perfluoroalkyl acids in consumer products, building materials and wastes. Chemosphere. 2016;164:322-9. https://doi. org/10.1016/j.chemosphere.2016.08.112.

2. Schaider LA, Balan SA, Blum A, Andrews DQ, Strynar MJ, Dickinson ME, et al. Fluorinated compounds in U.S. fast food packaging. Environ Sci Technol Lett. 2017;4:105-11. https:// doi.org/10.1021/acs.estlett.6b00435.

3. Johnson MS, Buck RC, Cousins IT, et al. Estimating environmental hazard and risks from exposure to per- and polyfluoroalkyl substances (PFASs): outcome of a SETAC focused topic meeting. Environ Toxicol Chem 00:etc. 2020:4784. https://doi.org/10. 1002/etc. 4784

4. Gibbens S. Toxic ' forever chemicals ' more common in tap water than thought, report says. Natl Geogr Mag. 2020.

5. Buck RC, Franklin J, Berger U, Conder JM, Cousins IT, de Voogt $\mathrm{P}$, et al. Perfluoroalkyl and polyfluoroalkyl substances in the environment: terminology, classification, and origins. Integr Environ Assess Manag. 2011;7:513-41. https://doi.org/10.1002/ieam.258.
6. Poothong S, Papadopoulou E, Padilla-Sánchez JA, Thomsen C, Haug LS. Multiple pathways of human exposure to poly- and perfluoroalkyl substances (PFASs): from external exposure to human blood. Environ Int. 2020;134:105244. https://doi.org/10. 1016/j.envint.2019.105244.

7. Jian JM, Chen D, Han FJ, Guo Y, Zeng L, Lu X, et al. A short review on human exposure to and tissue distribution of per- and polyfluoroalkyl substances (PFASs). Sci Total Environ. 2018;636:1058-69. https://doi.org/10.1016/j.scitotenv.2018.04. 380.

8. Liu Y, D'Agostino LA, Qu G, et al. High-resolution mass spectrometry (HRMS) methods for nontarget discovery and characterization of poly- and per-fluoroalkyl substances (PFASs) in environmental and human samples. TrAC - Trends Anal Chem. 2019;121:115420. https://doi.org/10.1016/j.trac.2019.02.021.

9. Liu $\mathrm{W}, \mathrm{Wu} \mathrm{J}, \mathrm{He} \mathrm{W}, \mathrm{Xu} \mathrm{F}$. A review on perfluoroalkyl acids studies: environmental behaviors, toxic effects, and ecological and health risks. Ecosyst Heal Sustain. 2019;5:1-19. https://doi. org/10.1080/20964129.2018.1558031.

10. Ateia M, Maroli A, Tharayil N, Karanfil T. The overlooked shortand ultrashort-chain poly- and perfluorinated substances: a review. Chemosphere. 2019;220:866-82. https://doi.org/10.1016/j. chemosphere.2018.12.186. Review of the research completed on short-chain PFAS in the environment and water. Continues to describe analytical methods and removal techniques.

11. UNEP SC (2020) Alternatives to POPs.

12. Munoz G, Liu J, Vo Duy S, Sauvé S. Analysis of F-53B, Gen-X, ADONA, and emerging fluoroalkylether substances in environmental and biomonitoring samples: a review. Trends Environ Anal Chem. 2019;23:e00066. https://doi.org/10.1016/j.teac. 2019.e00066.

13. Sunderland EM, Hu XC, Dassuncao C, Tokranov AK, Wagner $\mathrm{CC}$, Allen JG. A review of the pathways of human exposure to poly- and perfluoroalkyl substances (PFASs) and present understanding of health effects. J Expo Sci Environ Epidemiol. 2018;29:131-47. https://doi.org/10.1038/s41370-018-0094-1.

14. Sungur Ş, Köroğlu M, Turgut F. Determination of perfluorooctanoic acid (PFOA) and perfluorooctane sulfonic acid (PFOS) in food and beverages. Int J Environ Anal Chem. 2018;98: 360-8. https://doi.org/10.1080/03067319.2018.1468440.

15. Sznajder-Katarzyńska K, Surma M, Cieślik I. A review of perfluoroalkyl acids (PFAAs) in terms of sources, applications, human exposure, dietary intake, toxicity, legal regulation, and methods of determination. J Chem 2019. 2019;2019:1-20. https://doi.org/10.1155/2019/2717528.

16. Jian JM, Guo Y, Zeng L, Liang-Ying L, Lu X, Wang F, et al. Global distribution of perfluorochemicals (PFCs) in potential human exposure source-a review. Environ Int. 2017;108:51-62. https://doi.org/10.1016/j.envint.2017.07.024.

17. Dreyer A, Kirchgeorg T, Weinberg I, Matthias V. Particle-size distribution of airborne poly- and perfluorinated alkyl substances. Chemosphere. 2015;129:142-9. https://doi.org/10.1016/j. chemosphere.2014.06.069.

18. Han D, Ma Y, Huang C, Zhang X, Xu H, Zhou Y, et al. Occurrence and source apportionment of perfluoroalkyl acids (PFAAs) in the atmosphere in China. Atmos Chem Phys. 2019;19:14107-17. https://doi.org/10.5194/acp-19-14107-2019.

19. Yamazaki E, Taniyasu S, Noborio K, Eun H, Thaker P, Kumar NJI, et al. Accumulation of perfluoroalkyl substances in lysimetergrown rice in Japan using tap water and simulated contaminated water. Chemosphere. 2019;231:502-9. https://doi.org/10.1016/j. chemosphere.2019.05.022.

20. Zhao H, Qu B, Guan Y, et al. Influence of salinity and temperature on uptake of perfluorinated carboxylic acids (PFCAs) by 
hydroponically grown wheat (Triticum aestivum L.). Springerplus 5. 2016. https://doi.org/10.1186/s40064-016-2016-9.

21. Li P, Oyang X, Xie X, Li Z, Yang H, Xi J, et al. Phytotoxicity induced by perfluorooctanoic acid and perfluorooctane sulfonate via metabolomics. J Hazard Mater. 2019;389:121852. https://doi. org/10.1016/j.jhazmat.2019.121852.

22. Scher DP, Kelly JE, Huset CA, et al. Occurrence of perfluoroalkyl substances (PFAS) in garden produce at homes with a history of PFAS-contaminated drinking water. Chemosphere. 2018;196: 548-55. https://doi.org/10.1016/j.chemosphere.2017.12.179. Edible portions of plants were collected from gardens at 20 homes within a water district, along with water samples and soil samples. Water concentrations for homes in the district were reported to have PFAS detected in all unfiltered samples. PFBA was found in water samples $(85 \%)$ at high concentrations along with PFPeA (40\%). Related concentration of PFBA in floret, leaves, and seeds to water or irrigation or watering events. Indicated that (a) PFCAs preferred to PFSAs, (2) short-chain PFAAs bioaccumulated more, (3) species have uptake differences, and (4) plant-uptake differences between plant components.

23. Dalahmeh S, Tirgani S, Komakech AJ, Niwagaba CB, Ahrens L. Per- and polyfluoroalkyl substances (PFASs) in water, soil and plants in wetlands and agricultural areas in Kampala, Uganda. Sci Total Environ. 2018;631-632:660-7. https://doi.org/10.1016/ j.scitotenv.2018.03.024.

24. Nascimento RA, DBO N, Bizkarguenaga E, et al. Sulfluramid use in Brazilian agriculture: a source of per- and polyfluoroalkyl substances (PFASs) to the environment. Environ Pollut. 2018;242: 1436-43. https://doi.org/10.1016/j.envpol.2018.07.122. Sulfuramid (EtFOSA) is a precursor to PFOS, FOSAA, FOSA, and PFOA. Half-life of EtFOSA in the soil is short, so detection of FOSA and PFOS degredation products indicates use of sulfuramid contributes to PFAS contamination in Brazil. Soil samples reported PFAS, linear and branched PFOS detected at concentrations $<20$ up to $3770 \mathrm{pg} / \mathrm{g}$ $(1490 \mathrm{pg} / \mathrm{g}$ mean). PFAS were also found in river water, coastal water, and coastal sediments.

25. Zabaleta I, Bizkarguenaga E, Nunoo DBO, Schultes L, Leonel J, Prieto A, et al. Biodegradation and uptake of the pesticide sulfluramid in a soil-carrot mesocosm. Environ Sci Technol. 2018;52:2603-11. https://doi.org/10.1021/acs.est.7b03876.

26. Baduel C, Mueller JF, Rotander A, Corfield J, Gomez-Ramos MJ. Discovery of novel per- and polyfluoroalkyl substances (PFASs) at a fire fighting training ground and preliminary investigation of their fate and mobility. Chemosphere. 2017;185:1030-8. https:// doi.org/10.1016/j.chemosphere.2017.06.096.

27. Gallen C, Drage D, Kaserzon S, et al. Occurrence and distribution of brominated flame retardants and perfluoroalkyl substances in Australian landfill leachate and biosolids. J Hazard Mater. 2016;312:55-64. https://doi.org/10.1016/j.jhazmat.2016.03.031. Biosolids from 16 Australian water treatment plants were tested in addition to landfill leachate for PFAS, PBDEs, and HBCDDs (hexabromocyclodecane). BDE-209 and PFOS were detected at the highest concentrations in biosolids.

28. Navarro I, de la Torre A, Sanz P, Porcel MÁ, Pro J, Carbonell G, et al. Uptake of perfluoroalkyl substances and halogenated flame retardants by crop plants grown in biosolids-amended soils. Environ Res. 2017;152:199-206. https://doi.org/10.1016/j. envres.2016.10.018.

29. Navarro I, de la Torre A, Sanz P, Porcel MÁ, Carbonell G, Martínez MÁ. Transfer of perfluorooctanesulfonate (PFOS), decabrominated diphenyl ether (BDE-209) and Dechlorane Plus (DP) from biosolid-amended soils to leachate and runoff water. Environ Chem. 2018;15:195. https://doi.org/10.1071/EN18032.
30. Chu S, Letcher RJ. Side-chain fluorinated polymer surfactants in aquatic sediment and biosolid-augmented agricultural soil from the Great Lakes basin of North America. Sci Total Environ. 2017;607-608:262-70. https://doi.org/10.1016/j.scitotenv.2017. 06.252 .

31. Stahl T, Gassmann M, Falk S, Brunn H. Concentrations and distribution patterns of perfluoroalkyl acids in sewage sludge and in biowaste in Hesse, Germany. J Agric Food Chem. 2018;66: 10147-53. https://doi.org/10.1021/acs.jafc.8b03063.

32. Armstrong DL, Lozano N, Rice CP, Ramirez M, Torrents A. Temporal trends of perfluoroalkyl substances in limed biosolids from a large municipal water resource recovery facility. J Environ Manag. 2016;165:88-95. https://doi.org/10.1016/j.jenvman.2015. 09.023 .

33.• Letcher RJ, Chu S, Smyth SA. Side-chain fluorinated polymer surfactants in biosolids from wastewater treatment plants. J Hazard Mater. 2020;388:122044. https://doi.org/10.1016/j. jhazmat.2020.122044. Reported side-chain fluorinated polymer surfactants from Scotchgard ${ }^{\mathrm{TM}}$ fabric protectors, commonly quantified PFAS, and total fluorine in biosolids from Canadian WWTPs. Concentrations from two polymers utilized prior to and after 2002 ranged from 1.1 to $105 \mathrm{ng} / \mathrm{g} \mathrm{dw}$ and 37.5 to $2051 \mathrm{ng} / \mathrm{g} \mathrm{dw}$, respectively, and were 30 times higher than that of 22 PFAS tested. Demonstrates how underestimation of PFAS in biosolids occurs without additional PFAS to be included in analytical methods and nontarget monitoring of PFAS.

34. Bizkarguenaga E, Zabaleta I, Prieto A, Fernández LA, Zuloaga O. Uptake of 8:2 perfluoroalkyl phosphate diester and its degradation products by carrot and lettuce from compost-amended soil. Chemosphere. 2016;152:309-17. https://doi.org/10.1016/j. chemosphere.2016.02.130.

35. Choi YJ, Kim Lazcano R, Yousefi P, Trim H, Lee LS. Perfluoroalkyl acid characterization in U.S. municipal organic solid waste composts. Environ Sci Technol Lett. 2019;6:372-7. https://doi.org/10.1021/acs.estlett.9b00280.

36. Liu Z, Lu Y, Song X, Jones K, Sweetman AJ, Johnson AC, et al. Multiple crop bioaccumulation and human exposure of perfluoroalkyl substances around a mega fluorochemical industrial park, China: implication for planting optimization and food safety. Environ Int. 2019;127:671-84. https://doi.org/10.1016/j. envint.2019.04.008.

37. Bao J, Yu WJ, Liu Y, Wang X, Jin YH, Dong GH. Perfluoroalkyl substances in groundwater and home-produced vegetables and eggs around a fluorochemical industrial park in China. Ecotoxicol Environ Saf. 2019;171:199-205. https://doi.org/10. 1016/j.ecoenv.2018.12.086.

38. Brown JB, Conder JM, Arblaster JA, Higgins CP. Assessing human health risks from per- and polyfluoroalkyl substance (PFAS)impacted vegetable consumption: a tiered modeling approach. Environ Sci Technol. 2020. https://doi.org/10.1021/acs.est. 0c03411.

39. Collivignarelli MC, Abbà A, Frattarola A, Carnevale Miino M, Padovani S, Katsoyiannis I, et al. Legislation for the reuse of biosolids on agricultural land in Europe: overview. Sustain. 2019;11:1-22. https://doi.org/10.3390/su11216015.

40. Navarro I, de la Torre A, Sanz P, Fernández C, Carbonell G, Martínez MÁ. Environmental risk assessment of perfluoroalkyl substances and halogenated flame retardants released from biosolids-amended soils. Chemosphere. 2018;210:147-55. https://doi.org/10.1016/j.chemosphere.2018.07.007.

41. Weber R, Bell L, Watson A, Petrlik J, Paun MC, Vijgen J. Assessment of pops contaminated sites and the need for stringent soil standards for food safety for the protection of human health. Environ Pollut. 2019;249:703-15. https://doi.org/10.1016/j. envpol.2019.03.066. 
42.• Ghisi R, Vamerali T, Manzetti S. Accumulation of perfluorinated alkyl substances (PFAS) in agricultural plants: a review. Environ Res. 2019;169:326-41. https://doi.org/10.1016/j.envres.2018.10. 023. The first review to outline PFAS in agriculture. Discussed sources from irrigation, land-applied biosolids, and atmospheric depositions. Uptake from studies reviewed included plant protein contribution, root surface area and biomass, water evapotranspiration (transpiration factor), and PFAS chain length dynamics.

43. OECD. Toward a new comprehensive global database of per- and polyfluoroalkyl substances (PFASs): summary report on updating the OECD 2007 list of per- and polyfluoroalkyl substances (PFASs). Ser Risk Manag. 2018;39:1-24.

44. Zhi Y, Liu J. Sorption and desorption of anionic, cationic and zwitterionic polyfluoroalkyl substances by soil organic matter and pyrogenic carbonaceous materials. Chem Eng J. 2018;346: 682-91. https://doi.org/10.1016/j.cej.2018.04.042.

45. Xiao F, Jin B, Golovko SA, Golovko MY, Xing B. Sorption and desorption mechanisms of cationic and zwitterionic per- and polyfluoroalkyl substances in natural soils: thermodynamics and hysteresis. Environ Sci Technol. 2019;53:11818-27. https://doi. org/10.1021/acs.est.9b05379.

46. Nakayama SF, Yoshikane M, Onoda Y, Nishihama Y, IwaiShimada M, Takagi M, et al. Worldwide trends in tracing polyand perfluoroalkyl substances (PFAS) in the environment. TrAC Trends Anal Chem. 2019;121:115410. https://doi.org/10.1016/j. trac.2019.02.011.

47. Martínez-Bueno MJ, Gómez Ramos MJ, Bauer A, FernándezAlba AR. An overview of non-targeted screening strategies based on high resolution accurate mass spectrometry for the identification of migrants coming from plastic food packaging materials. Trends Anal Chem. 2019;110:191-203. https://doi.org/10.1016/j. trac.2018.10.035.

48. Liu J, Mejia Avendaño S. Microbial degradation of polyfluoroalkyl chemicals in the environment: a review. Environ Int. 2013;61:98-114. https://doi.org/10.1016/j.envint. 2013.08.022

49. Zhang S, Lu X, Wang N, Buck RC. Biotransformation potential of 6:2 fluorotelomer sulfonate (6:2 FTSA) in aerobic and anaerobic sediment. Chemosphere. 2016;154:224-30. https://doi.org/10. 1016/j.chemosphere.2016.03.062.

50. Koch A, Aro R, Wang T, Yeung LWY. Towards a comprehensive analytical workflow for the chemical characterisation of organofluorine in consumer products and environmental samples. TrAC - Trends Anal Chem. 2020;123:115423. https://doi.org/10. 1016/j.trac.2019.02.024.

51. Zhao S, Zhou T, Wang B, Zhu L, Chen M, Li D, et al. Different biotransformation behaviors of perfluorooctane sulfonamide in wheat (Triticum aestivum L.) from earthworms (Eisenia fetida). J Hazard Mater. 2018;346:191-8. https://doi.org/10.1016/j. jhazmat.2017.12.018.

52. Vedagiri UK, Anderson RH, Loso HM, Schwach CM. Ambient levels of PFOS and PFOA in multiple environmental media. Remediat J. 2018;28:9-51. https://doi.org/10.1002/rem.21548.

53. Rankin K, Mabury SA, Jenkins TM, Washington JW. A North American and global survey of perfluoroalkyl substances in surface soils: distribution patterns and mode of occurrence. Chemosphere. 2016;161:333-41. https://doi.org/10.1016/j. chemosphere.2016.06.109.

54. Kim H, Ekpe OD, Lee JH, Kim DH, Oh JE. Field-scale evaluation of the uptake of perfluoroalkyl substances from soil by rice in paddy fields in South Korea. Sci Total Environ. 2019;671:714 21. https://doi.org/10.1016/j.scitotenv.2019.03.240.

55. Zhang $\mathrm{M}$, Wang $\mathrm{P}, \mathrm{Lu} \mathrm{Y}$, Lu X, Zhang A, Liu Z, et al. Bioaccumulation and human exposure of perfluoroalkyl acids (PFAAs) in vegetables from the largest vegetable production base of China. Environ Int. 2020;135:105347. https://doi.org/10.1016/ j.envint.2019.105347.

56. Riaz U, Murtaza G, Saifullah FM. Influence of different sewage sludges and composts on growth, yield, and trace elements accumulation in rice and wheat. L Degrad Dev. 2018;29:1343-52. https://doi.org/10.1002/ldr.2925.

57. Kladivko EJ, Nelson DW. Changes in soil properties from application of anaerobic sludge. J Water Pollut Control Fed. 1979;51: 325-32.

58. Lu Q, He ZL, Stoffella PJ. Land application of biosolids in the USA: a review. Appl Environ Soil Sci 2012. 2012;2012:1-11. https://doi.org/10.1155/2012/201462.

59. Kim Lazcano R, Choi YJ, Mashtare ML, Lee LS. Characterizing and comparing per- and polyfluoroalkyl substances in commercially available biosolid and organic non-biosolid-based products. Environ Sci Technol. 2020;54:8640-8. https://doi.org/10.1021/ acs.est.9b07281.

60. Li Y, Oliver DP, Kookana RS. A critical analysis of published data to discern the role of soil and sediment properties in determining sorption of per and polyfluoroalkyl substances (PFASs). Sci Total Environ. 2018;(628-629):110-20. https://doi.org/10. 1016/j.scitotenv.2018.01.167.

61. Eriksson U, Haglund P, Kärrman A. Contribution of precursor compounds to the release of per- and polyfluoroalkyl substances (PFASs) from waste water treatment plants (WWTPs). J Environ Sci. 2017;61:80-90. https://doi.org/10.1016/j.jes.2017.05.004

62. Wen B, Li L, Zhang H, Ma Y, Shan XQ, Zhang S. Field study on the uptake and translocation of perfluoroalkyl acids (PFAAs) by wheat (Triticum aestivum L.) grown in biosolids-amended soils. Environ Pollut. 2014;184:547-54. https://doi.org/10.1016/j. envpol.2013.09.040.

63. Blaine AC, Rich CD, Hundal LS, Lau C, Mills MA, Harris KM, et al. Uptake of perfluoroalkyl acids into edible crops via land applied biosolids: field and greenhouse studies. Environ Sci Technol. 2013;47:14062-9. https://doi.org/10.1021/es403094q.

64. Sepulvado JG, Blaine AC, Hundal LS, Higgins CP. Occurrence and fate of perfluorochemicals in soil following the land application of municipal biosolids. Environ Sci Technol. 2011;45:810612. https://doi.org/10.1021/es103903d.

65. Faubert P, Bélisle CL, Bertrand N, Bouchard S, Chantigny MH, Paré $\mathrm{MC}$, et al. Land application of pulp and paper mill sludge may reduce greenhouse gas emissions compared to landfilling. Resour Conserv Recycl. 2019;150:104415. https://doi.org/10. 1016/j.resconrec.2019.104415.

66. Li P, Oyang X, Zhao Y, Tu T, Tian X, Li L, et al. Occurrence of perfluorinated compounds in agricultural environment, vegetables, and fruits in regions influenced by a fluorine-chemical industrial park in China. Chemosphere. 2019;225:659-67. https://doi. org/10.1016/j.chemosphere.2019.03.045.

67. Dauchy X, Boiteux V, Colin A, Hémard J, Bach C, Rosin C, et al. Deep seepage of per- and polyfluoroalkyl substances through the soil of a firefighter training site and subsequent groundwater contamination. Chemosphere. 2019;214:729-37. https://doi.org/10. 1016/j.chemosphere.2018.10.003.

68. Campos Pereira H, Ullberg M, Kleja DB, Gustafsson JP, Ahrens L. Sorption of perfluoroalkyl substances (PFASs) to an organic soil horizon - effect of cation composition and $\mathrm{pH}$. Chemosphere. 2018;207:183-91. https://doi.org/10.1016/j.chemosphere.2018. 05.012 .

69. McLachlan MS, Felizeter S, Klein M, et al. Fate of a perfluoroalkyl acid mixture in an agricultural soil studied in lysimeters. Chemosphere. 2019;223:180-7. https://doi.org/10. 1016/J.CHEMOSPHERE.2019.02.012.

70. Barzen-Hanson KA, Davis SE, Kleber M, Field JA. Sorption of fluorotelomer sulfonates, fluorotelomer sulfonamido betaines, and a fluorotelomer sulfonamido amine in national foam aqueous film- 
forming foam to soil. Environ Sci Technol. 2017;51:12394-404. https://doi.org/10.1021/acs.est.7b03452.

71. Qian J, Shen M, Wang P, Wang C, Hou J, Ao Y, et al. Adsorption of perfluorooctane sulfonate on soils: effects of soil characteristics and phosphate competition. Chemosphere. 2017;168:1383-8. https://doi.org/10.1016/j.chemosphere.2016.11.114.

72. Park S, Lee LS, Ross I, Hurst J. Evaluating perfluorooctanesulfonate oxidation in permanganate systems. Environ Sci Pollut Res. 2020;27:13976-84. https://doi.org/10. 1007/s11356-020-07803-7.

73. Lyu Y, Brusseau ML, Chen W, Yan N, Fu X, Lin X. Adsorption of PFOA at the air-water interface during transport in unsaturated porous media. Environ Sci Technol. 2018;52:7745-53. https://doi. org/10.1021/acs.est.8b02348.

74. Brusseau ML, Yan N, Van Glubt S, et al. Comprehensive retention model for PFAS transport in subsurface systems. Water Res. 2019;148:41-50. https://doi.org/10.1016/j.watres.2018.10.035.

74.•Zhang L, Sun H, Wang Q, et al. Uptake mechanisms of perfluoroalkyl acids with different carbon chain lengths (C2-C8) by wheat (Triticum acstivnm L.). Sci Total Environ. 2019;654:19 27. https://doi.org/10.1016/j.scitotenv.2018.10.443. Determined that PFCA uptake is an active process (carrier protein mediated), and aquaporins and the anion channel are additional uptake routes for $\mathrm{C} 2$ and $\mathrm{C} 3$ compounds. Ultrashort-chain PFAS had rapid uptake into the wheat roots that did not reach steady state compared to longer-chain PFAS where uptake slowed, and C8 PFAS where uptake reached steady state within $32 \mathrm{~h}$.

76. Zhao H, Guan Y, Qu B. PFCA uptake and translocation in dominant wheat species (Triticum aestivum L.). Int J Phytoremediation. 2018;20:68-74. https://doi.org/10.1080/ 15226514.2017.1337066.

76. Lin Q, Zhou C, Chen L, et al. Accumulation and associated phytotoxicity of novel chlorinated polyfluorinated ether sulfonate in wheat seedlings. Chemosphere. 2020;249:126447. https://doi.org/ 10.1016/j.chemosphere.2020.126447. F-53B is an electroplating alternative to PFOS in China. Uptake and phytotoxicity were observed in the presence of Cl-PFAES. Uptake was observed mainly in roots, though 6:2 CI-PFAES was comparable to PFOS uptake, and phytotoxic effects were greater than those of PFOS.

78. Qu B, Zhao H, Zhou J. Toxic effects of perfluorooctane sulfonate (PFOS) on wheat (Triticum aestivum L.) plant. Chemosphere. 2010;79:555-60. https://doi.org/10.1016/j.chemosphere.2010.02. 012 .

79. Lan Z, Zhou M, Yao Y, Sun H. Plant uptake and translocation of perfluoroalkyl acids in a wheat-soil system. Environ Sci Pollut Res. 2018;25:30907-16. https://doi.org/10.1007/s11356-0183070-3.

80. Zhao S, Fang S, Zhu L, Liu L, Liu Z, Zhang Y. Mutual impacts of wheat (Triticum aestivum L.) and earthworms (Eisenia fetida) on the bioavailability of perfluoroalkyl substances (PFASs) in soil. Environ Pollut. 2014;184:495-501. https://doi.org/10.1016/j. envpol.2013.09.032.

81. Zhao S, Fan Z, Sun L, Zhou T, Xing Y, Liu L. Interaction effects on uptake and toxicity of perfluoroalkyl substances and cadmium in wheat (Triticum aestivum L.) and rapeseed (Brassica campestris L.) from co-contaminated soil. Ecotoxicol Environ Saf. 2017;137: 194-201. https://doi.org/10.1016/j.ecoenv.2016.12.007.

82. Stahl T, Heyn J, Thiele H, Hüther J, Failing K, Georgii S, et al. Carryover of perfluorooctanoic acid (PFOA) and perfluorooctane sulfonate (PFOS) from soil to plants. Arch Environ Contam Toxicol. 2009;57:289-98. https://doi.org/10.1007/s00244-0089272-9.

83. Wen B, Pan Y, Shi X, Zhang H, Hu X, Huang H, et al. Behavior of $\mathrm{N}$-ethyl perfluorooctane sulfonamido acetic acid (N-EtFOSAA) in biosolids amended soil-plant microcosms of seven plant species: accumulation and degradation. Sci Total Environ. 2018;642:36673. https://doi.org/10.1016/j.scitotenv.2018.06.073.

84. Wen B, Wu Y, Zhang H, Liu Y, Hu X, Huang H, et al. The roles of protein and lipid in the accumulation and distribution of perfluorooctane sulfonate (PFOS) and perfluorooctanoate (PFOA) in plants grown in biosolids-amended soils. Environ Pollut. 2016;216:682-8. https://doi.org/10.1016/j.envpol.2016. 06.032 .

85. Krippner J, Falk S, Brunn H, Georgii S, Schubert S, Stahl T. Accumulation potentials of perfluoroalkyl carboxylic acids (PFCAs) and perfluoroalkyl sulfonic acids (PFSAs) in maize (Zea mays). J Agric Food Chem. 2015;63:3646-53. https://doi. org/10.1021/acs.jafc.5b00012.

86. Lan Z, Yao Y, Xu J, Chen H, Ren C, Fang X, et al. Novel and legacy per- and polyfluoroalkyl substances (PFASs) in a farmland environment: soil distribution and biomonitoring with plant leaves and locusts. Environ Pollut. 2020;263:114487. https://doi.org/10. 1016/j.envpol.2020.114487.

87. Zhao S, Liang T, Zhou T, Li D, Wang B, Zhan J, et al. Biotransformation and responses of antioxidant enzymes in hydroponically cultured soybean and pumpkin exposed to perfluorooctane sulfonamide (FOSA). Ecotoxicol Environ Saf. 2018;161:669-75. https://doi.org/10.1016/j.ecoenv.2018.06.048.

88. Defence AGD of (2017) PFAS in plants - 2017 Study findings Army Aviation Centre Oakey Stage 2C Environmental Investigation Background to the Plant Study.

89. Shigei M, Ahren L, Hazaymeh A, Dalahmeh S. Per- and polyfluoroalkyl substances in water and soil in wastewaterirrigated farmland in Jordan. Sci Total Environ. 2020;716: 137057. https://doi.org/10.1016/j.scitotenv.2020.137057.

90. Li P, Oyang X, Xie X, Guo Y, Li Z, Xi J, et al. Perfluorooctanoic acid and perfluorooctane sulfonate co-exposure induced changes of metabolites and defense pathways in lettuce leaves. Environ Pollut. 2019;256:113512. https://doi.org/10.1016/j.envpol.2019. 113512.

91. Felizeter S, McLachlan MS, de Voogt P. Uptake of perfluorinated alkyl acids by hydroponically grown lettuce (Lactuca sativa ). Environ Sci Technol. 2012;46:11735-43. https://doi.org/10. 1021/es302398u.

91. Yu P-F, Xiang L, Li X-H, et al (2018) Cultivar-dependent accumulation and translocation of perfluorooctanesulfonate among lettuce (Lactuca sativa L.) cultivars grown on perfluorooctanesulfonate-contaminated soil. J Agric Food Chem 66:13096-13106. https://doi.org/10.1021/acs.jafc. $8 \mathrm{~b} 04548$. Accumulation comparisons between 3 lettuce subtypes (14 romaine lettuce cultivars, 7 leaf lettuce cultivars, and 5 head cultivars). Leaf lettuce subtypes had the lowest PFOS accumulations, but all subtypes had differences in accumulation between treatments and cultivars. PFOS did not influence transpiration or protein content (no toxicity determined by the values measured). Infers that contaminated fields should be planted with cultivars that take up less PFOS including leaf lettuce subtype with low protein content, low stomatal conductance, and low transpiration. These subtypes have lower protein-mediated transpiration and it is suggested that proteins in shoots and roots may be carriers (uptake and translocation mechanism), so carrier or channel proteins should be evaluated to determine which proteins are present in low PFOS accumulating cultivars.

93. Blaine AC, Rich CD, Sedlacko EM, Hyland KC, Stushnoff C, Dickenson ERV, et al. Perfluoroalkyl acid uptake in lettuce ( Lactuca sativa ) and strawberry ( Fragaria ananassa ) irrigated with 
reclaimed water. Environ Sci Technol. 2014;48:14361-8. https:// doi.org/10.1021/es504150h.

94. Lal MS, Megharaj M, Naidu R, Bahar MM. Uptake of perfluorooctane sulfonate (PFOS) by common home-grown vegetable plants and potential risks to human health. Environ Technol Innov. 2020;19:100863. https://doi.org/10.1016/j.eti.2020. 100863.

95. Eun H, Yamazaki E, Taniyasu S, Miecznikowska A, Falandysz J, Yamashita N. Evaluation of perfluoroalkyl substances in fieldcultivated vegetables. Chemosphere. 2020;239:124750. https:/ doi.org/10.1016/j.chemosphere.2019.124750.

96. Felizeter S, McLachlan MS, De Voogt P. Root uptake and translocation of perfluorinated alkyl acids by three hydroponically grown crops. J Agric Food Chem. 2014;62:3334 42. https://doi. org $/ 10.1021 /$ jf500674j.

97. Blaine AC, Rich CD, Sedlacko EM, Hundal LS, Kumar K, Lau C, et al. Perfluoroalkyl acid distribution in various plant compartments of edible crops grown in biosolids-amended soils. Environ Sci Technol. 2014;48:7858-65. https://doi.org/10.1021/ es500016s.

98. Lechner M, Knapp H. Carryover of perfluorooctanoic acid (PFOA) and perfluorooctane sulfonate (PFOS) from soil to plant and distribution to the different plant compartments studied in cultures of carrots ( Daucus carota ssp. Sativus ), potatoes ( Solanum tuberosum ), and cucu. J Agric Food Chem. 2011;59: 11011-8. https://doi.org/10.1021/jf201355y.

99. Bao J, Li CL, Liu Y, Wang X, Yu WJ, Liu ZQ, et al. Bioaccumulation of perfluoroalkyl substances in greenhouse vegetables with long-term groundwater irrigation near fluorochemical plants in Fuxin, China. Environ Res. 2020;188:109751. https:// doi.org/10.1016/j.envres.2020.109751.

100. Zhao S, Liang T, Zhu L, Yang L, Liu T, Fu J, et al. Fate of 6:2 fluorotelomer sulfonic acid in pumpkin (Cucurbita maxima L.) based on hydroponic culture: uptake, translocation and biotransformation. Environ Pollut. 2019;252:804-12. https://doi.org/10. 1016/j.envpol.2019.06.020.

101. Gobelius L, Lewis J, Ahrens L. Plant uptake of per- and polyfluoroalkyl substances at a contaminated fire training facility to evaluate the phytoremediation potential of various plant species. Environ Sci Technol. 2017;51:12602-10. https://doi.org/10.1021/ acs.est.7b02926.

101. Gredelj A, Nicoletto C, Polesello S, et al. Uptake and translocation of perfluoroalkyl acids ( PFAAs ) in hydroponically grown red chicory (Cichorium intybus L.): growth and developmental toxicity, comparison with growth in soil and bioavailability implications. Sci Total Environ. 2020;720:137333. https://doi.org/10. 1016/j.scitotenv.2020.137333 Plant uptake model built on prior experiments in soil. Creates comparisons between soil and hydroponically grown chicory. Contributed high accumulation of perfluoroalkyl acids in crops to root to xylem partition coefficients. Describes a dynamic system with no rapid uptake, but with chemical mass increasing continuously with transpiration.

103. Sharma N, Barion G, Shrestha I, Ebinezer LB, Trentin AR, Vamerali T, et al. Accumulation and effects of perfluoroalkyl substances in three hydroponically grown Salix L. species. Ecotoxicol Environ Saf. 2020;191:110150. https://doi.org/10.1016/j.ecoenv. 2019.110150

104. Gredelj A, Nicoletto C, Valsecchi S, et al (2020) Uptake and translocation of perfluoroalkyl acids (PFAA) in red chicory (Cichorium intybus L.) under various treatments with precontaminated soil and irrigation water. Sci Total Environ 708: 134766. https://doi.org/10.1016/j.scitotenv.2019.134766.

104. Müller CE, GH LF, Timofte AE, et al. Competing mechanisms for perfluoroalkyl acid accumulation in plants revealed using an
Arabidopsis model system. Environ Toxicol Chem. 2016;35: 1138-47. https://doi.org/10.1002/etc.3251. Established uptake models for PFAAs in hydroponically grown thale cress (Arabidopsis thaliana) by examining uptake and depuration in plant roots and shoots as well as sorption to dead root tissue. Root concentrations increased via adsorption to apoplast and symplast and quickly reached a steady state for 9 PFAAs; however, PFBA saturation kinetics were reduced and indicated increased transport. Depuration occurred completely in roots for 9 PFAAs excluding PFBA but not for PFAAs translocated to shoots. Thus, proposing a 2compartment uptake model for PFBA and a 1-compartment model for the other PFAAs examined.

106. McLachlan MS, Felizeter S, Klein M, et al. Fate of a perfluoroalkyl acid mixture in an agricultural soil studied in lysimeters. Chemosphere. 2019;223:180-7. https://doi.org/10. 1016/j.chemosphere.2019.02.012.

107. Bräunig J, Baduel C, Barnes CM, Mueller JF. Leaching and bioavailability of selected perfluoroalkyl acids (PFAAs) from soil contaminated by firefighting activities. Sci Total Environ. 2019;646:471-9. https://doi.org/10.1016/j.scitotenv.2018.07.231.

108. Zhao S, Zhou T, Zhu L, Wang B, Li Z, Yang L, et al. Uptake, translocation and biotransformation of N-ethyl perfluorooctanesulfonamide (N-EtFOSA) by hydroponically grown plants. Environ Pollut. 2018;235:404-10. https://doi.org/ 10.1016/j.envpol.2017.12.053.

109. Barberon M. The endodermis as a checkpoint for nutrients. New Phytol. 2017;213:1604-10. https://doi.org/10.1111/nph.14140.

110. Doblas VG, Geldner N, Barberon M. The endodermis, a tightly controlled barrier for nutrients. Curr Opin Plant Biol. 2017;39: 136-43. https://doi.org/10.1016/j.pbi.2017.06.010.

111. Wang TT, Ying GG, He LY, Liu YS, Zhao JL. Uptake mechanism, subcellular distribution, and uptake process of perfluorooctanoic acid and perfluorooctane sulfonic acid by wetland plant Alisma orientale. Sci Total Environ. 2020;733:139383. https://doi.org/10.1016/j.scitotenv.2020.139383.

112. Liska D, Martinka M, Kohanova J, Lux A. Asymmetrical development of root endodermis and exodermis in reaction to abiotic stresses. Ann Bot. 2016;118:667-74. https://doi.org/10.1093/aob/ mow047.

113. Wang P, Calvo-Polanco M, Reyt G, Barberon M, Champeyroux C, Santoni V, et al. Surveillance of cell wall diffusion barrier integrity modulates water and solute transport in plants. Sci Rep. 2019;9:1-11. https://doi.org/10.1038/s41598-019-40588-5.

114. Seo SH, Son MH, Shin ES, Choi SD, Chang YS. Matrix-specific distribution and compositional profiles of perfluoroalkyl substances (PFASs) in multimedia environments. J Hazard Mater. 2019;364:19-27. https://doi.org/10.1016/j.jhazmat.2018.10.012.

115. Liu Y, Hou X, Chen W, Kong W, Wang D, Liu J, et al. Occurrences of perfluoroalkyl and polyfluoroalkyl substances in tree bark: interspecies variability related to chain length. Sci Total Environ. 2019;689:1388-95. https://doi.org/10.1016/j.scitotenv. 2019.06.454.

116. Zhang W, Zhang D, Zagorevski DV, Liang Y. Exposure of Juncus effusus to seven perfluoroalkyl acids: uptake, accumulation and phytotoxicity. Chemosphere. 2019;233:300-8. https://doi.org/10. 1016/j.chemosphere.2019.05.258.

117. Brambilla G, D'Hollander W, Oliaei F, et al. Pathways and factors for food safety and food security at PFOS contaminated sites within a problem based learning approach. Chemosphere. 2015;129: 192-202. https://doi.org/10.1016/j.chemosphere.2014.09.050.

Publisher's Note Springer Nature remains neutral with regard to jurisdictional claims in published maps and institutional affiliations. 